\title{
THE RISE OF ROBOTS AND THE FALL OF ROUTINE JOBS
}

Gaaitzen J. de Vries, Elisabetta Gentile, Sébastien Miroudot, and Konstantin M. Wacker

NO. 619

August 2020
ADB ECONOMICS WORKING PAPER SERIES 


\section{ADB Economics Working Paper Series}

\section{The Rise of Robots and the Fall of Routine Jobs}

Gaaitzen J. de Vries, Elisabetta Gentile, Sébastien Miroudot, and Konstantin M. Wacker

No. 619 | August 2020
Gaaitzen J. de Vries (g.j.de.vries@rug.nl) is an associate professor from the Faculty of Economics and Business, University of Groningen, The Netherlands. Elisabetta Gentile (egentile@adb.org) is an economist from the Asian Development Bank. Sébastien Miroudot (sebastien.miroudot@oecd.org) is a senior trade policy analyst from the Organisation for Economic Co-operation and Development (OECD), Trade and Agriculture Directorate, France. Konstantin M. Wacker (k.m.wacker@rug.nl) is an assistant professor from the Faculty of Economics and Business, University of Groningen, The Netherlands.

This project started as background research for the Asian Development Outlook 2018. We thank Donald Jay Bertulfo for excellent research assistantship. We thank all colleagues who offered help and advice, including Abdul Abiad, Rana Hasan, Yasuyuki Sawada, and Joseph E. Zveglich Jr. We also thank seminar attendees at the Asian Development Bank, and conference participants at the XXXI Villa Mondragone International Economic Seminar, the 57th Annual Meeting and Conference of the Philippine Economic Society, the Asian and Australasian Society of Labour Economics 2019 Conference, and the 1st LISER-IAB Conference on Digital Transformation and the Future of Work. 
(C) 2020 Asian Development Bank 6 ADB Avenue, Mandaluyong City, 1550 Metro Manila, Philippines

Tel +632 8632 4444; Fax +63286362444

www.adb.org

Some rights reserved. Published in 2020.

ISSN 2313-6537 (print), 2313-6545 (electronic)

Publication Stock No. WPS200236-2

DOI: http://dx.doi.org/10.22617/WPS200236-2

The views expressed in this publication are those of the authors and do not necessarily reflect the views and policies of the Asian Development Bank (ADB) or its Board of Governors or the governments they represent.

ADB does not guarantee the accuracy of the data included in this publication and accepts no responsibility for any consequence of their use. The mention of specific companies or products of manufacturers does not imply that they are endorsed or recommended by ADB in preference to others of a similar nature that are not mentioned.

By making any designation of or reference to a particular territory or geographic area, or by using the term "country" in this document, $A D B$ does not intend to make any judgments as to the legal or other status of any territory or area.

This work is available under the Creative Commons Attribution 3.0 IGO license (CC BY 3.0 IGO)

https://creativecommons.org/licenses/by/3.0/igo/. By using the content of this publication, you agree to be bound by the terms of this license. For attribution, translations, adaptations, and permissions, please read the provisions and terms of use at https://www.adb.org/terms-use\#openaccess.

This CC license does not apply to non-ADB copyright materials in this publication. If the material is attributed to another source, please contact the copyright owner or publisher of that source for permission to reproduce it. $\mathrm{ADB}$ cannot be held liable for any claims that arise as a result of your use of the material.

Please contact pubsmarketing@adb.org if you have questions or comments with respect to content, or if you wish to obtain copyright permission for your intended use that does not fall within these terms, or for permission to use the ADB logo.

Corrigenda to ADB publications may be found at http://www.adb.org/publications/corrigenda.

Note:

ADB recognizes "China” as the People's Republic of China.

The ADB Economics Working Paper Series presents data, information, and/or findings from ongoing research and studies to encourage exchange of ideas and to elicit comment and feedback about development issues in Asia and the Pacific. Since papers in this series are intended for quick and easy dissemination, the content may or may not be fully edited and may later be modified for final publication. 


\section{CONTENTS}

TABLES AND FIGURES

ABSTRACT

$\begin{array}{lll}\text { I. INTRODUCTION } & 1\end{array}$

II. THEORETICAL FRAMEWORK 2

III. METHODOLOGY 5

Endogeneity Concerns and 2-Stage Least Squares Estimation 5

$\begin{array}{lll}\text { IV. } & \text { DATA AND DESCRIPTIVE ANALYSIS } & 7\end{array}$

A. Occupations and Robots $\quad 7$

B. Descriptive Analysis 9

V. ECONOMETRIC RESULTS

A. Main Ordinary Least Squares and 2-Stage Least Squares Results 13

B. Robustness and Extensions 16

VI. CONCLUDING REMARKS 22

$\begin{array}{ll}\text { APPENDIX } & 23\end{array}$

$\begin{array}{ll}\text { REFERENCES } & 33\end{array}$ 


\section{TABLES AND FIGURES}

\section{TABLES}

$1 \quad$ Mapping Occupations to Tasks 8

2 Descriptive Statistics 10

3 Baseline Regression Results of Employment Growth and Change 14 in Routine Employment Share

4 Robot Adoption and Changes in Employment Shares by Task Type 16

5 Robot Adoption and Changes in the Employment Share of Production Workers 19

6 Accounting for Long-Term Industry Trends $\quad 20$

$7 \quad$ Global Industry Trends in Robot Adoption 21

A1.1 Industry codes $\quad 29$

A1.2 2-Stage Least Squares Results for Reaching and Handling 30

A1.3 Robustness Analysis 31

A1.4 Routine Task-Intensity of Occupations Grouped as ‘Production Workers' 32

\section{FIGURES}

$1 \quad$ Robots and the Routine Employment Share 11

2 Cross-Industry Variation in Instrumental Variables and Changes 12 in the Routine Employment Share

A1.1 Changes in Employment Shares by Economy and Task Type between 2005 and $2015 \quad 23$

A1.2 Changes in Employment Shares by Industry and Task Type between 2005 and $2015 \quad 24$

A1.3 Robotization by Economy in 2005 and 2015

A1.4 Robotization by Industry in 2005 and 2015

A1.5 Robotization by Industry in the People's Republic of China and Germany, 2015

A1.6 Residual Patterns for Main Ordinary Least Squares Specification 26

A1.7 Economy-Specific Ordinary Least Squares Coefficients 27

A1.8 Industry-Specific Ordinary Least Squares Coefficients 28 


\begin{abstract}
This paper examines the impact of industrial robots on jobs. We combine data on robot adoption and occupations by industry in 37 economies for the period 2005-2015. We exploit differences across industries in technical feasibility-defined as the industry's share of tasks replaceable by robots-to identify the impact of robot usage on employment. The data allow us to differentiate effects by the routine intensity of employment. We find that a rise in robot adoption relates significantly to a fall in the employment share of routine manual task-intensive jobs. This relation is observed in high-income economies, but not in emerging market and transition economies.
\end{abstract}

Keywords: employment, occupations, robots, tasks

JEL codes: E23, J23, O30 


\section{INTRODUCTION}

Rapid improvements in robot capabilities have fueled concerns about the implications of robot adoption for jobs. While the creation of autonomous robots with flexible 3D movement continues to be a major challenge to engineers, rapid progress is being made. Robots can now perform a variety of tasks, such as sealing, assembling, and handling tools. As robot capabilities continue to expand and unit prices fall, firms are intensifying investment in robots (Frey and Osborne 2017, Graetz and Michaels 2018, Acemoglu and Restrepo 2020). What is the impact of robot adoption on labor demand? Do robots substitute for tasks previously performed by workers?

The main contribution of this paper is to empirically study the impact of industrial robots on the occupational structure of the workforce across industries in a set of high-income as well as emerging market and transition economies (EMTEs). We combine a large and detailed occupations database with data on industrial robot deliveries from the International Federation of Robotics. The database on occupational employment from Reijnders and de Vries (2018) allows us to examine the share of employment in occupations with a high content of routine tasks - that is, tasks that can be performed by following a well-defined set of procedures. We delineate occupations along two dimensions of the characteristics of tasks performed, namely 'analytic' versus 'manual,' and 'routine' versus 'nonroutine." We thus distinguish four key occupational groupings, namely routine manual, routine analytic, nonroutine manual, and nonroutine analytic task-intensive occupations (as in Autor, Levy, and Murnane 2003; Reijnders and de Vries 2018; Cortes et al. 2020). We follow Graetz and Michaels (2018) in constructing measures of robot adoption by country-industry pairs and relate these to changes in occupational employment shares. Our sample covers 19 industries for 37 economies at varying levels of development from 2005 to 2015, and includes major users of industrial robots, such as the Peoples Republic of China (PRC), Japan, the Republic of Korea, Germany, and the United States (US). Our main finding is that country-industry pairs that saw a more rapid increase in robot adoption experienced larger reductions in the employment share of routine manual jobs.

Our approach is motivated by the following economic considerations. Firms produce a variety of products using a continuum of tasks (Acemoglu and Autor 2011), and these products differ in the number of tasks that can be performed by robots (Graetz and Michaels 2018). For example, the share of replaceable tasks by robots differs between apparel and automotive and appears larger in the latter. ${ }^{2}$ This gives rise to differences across industries in the technical feasibility of robots substituting tasks previously performed by humans. Advances in machine capabilities expand the set of tasks carried out by machines (Acemoglu and Restrepo 2018). Firms will adopt robots if it is technically feasible and the profit gains exceed the costs of purchasing and installing robots. Given higher wages in advanced countries, the technical constraints to robots replacing tasks are more likely to bind for firms in these countries. Hence, improvements in robot capabilities would result in a larger employment response in advanced countries compared to developing countries.

We use these economic insights in our analysis. In particular, the technical feasibility of adopting robots guides our instrumental variables (IV) strategy to identify the causal relation between robots and labor demand. Economic feasibility motivates our distinction of the impact of robot

\footnotetext{
The distinction between manual and analytic occupations is based on differences in the extent of mental versus physical activity.

2 See, for example, The Economist. 2017. "Sewing clothes still needs human hands. But for how much longer?" August 24.
} 
adoption between advanced and developing economies. Using two-stage least squares (2SLS) estimation, we find that robot adoption lowers the employment share of routine manual occupations. This relation is observed in high-income economies, but not in EMTEs.

This paper relates to recent studies that examine the impact of robot adoption on socioeconomic outcomes. Graetz and Michaels (2018) find that robot adoption contributed to an increase in productivity growth across industries in high-income countries between 1993 and 2007. Their findings suggest that robot adoption did not reduce employment, which is corroborated in this paper. This is also observed by Dauth et al. (2019), but not by Acemoglu and Restrepo (2020), who examine geographic variation in robot adoption across the US and find that robots are labor replacing. Dauth et al. (2019) use detailed linked employer-employee data for Germany to show that displacement effects are canceled out by reallocation effects, such that in the aggregate no employment effects from robot adoption are observed. Data availability did not allow Graetz and Michaels (2018) to examine the impact of robots on workers that perform different tasks. Yet, Autor (2015) emphasizes that workers with routine task-intensive occupations are most likely to be affected by automation. This paper aims to contribute to our understanding of the impact of robots on such occupational shifts.

The remainder of this paper is organized as follows. Section II reviews the key theoretical mechanisms between automation and labor demand. Section III describes the methodology and instrumental variables. Section IV documents patterns in the occupational structure of the workforce and robot adoption. Section $\vee$ empirically studies the impact of robot adoption on the task content of labor demand. Section VI concludes.

\section{THEORETICAL FRAMEWORK}

This section starts with a discussion of robot adoption in the context of a traditional capital-labor model. In this model, technology is factor-augmenting: it increases the efficiency of one of the production factors employed (Acemoglu and Autor 2011). The model puts the focus on the complementarity and substitutability between robots and tasks performed by workers. We then describe recent modeling efforts that emphasize the ability of machines to replace workers in a widening range of tasks (Acemoglu and Restrepo 2018). These models help to clarify mechanisms by which robots may impact labor demand and motivate our empirical analysis.

The models we describe analyse the impact of automation. Automation refers to computerassisted machines, robotics, and artificial intelligence (Acemoglu and Restrepo 2018). Thus, robots are a subset of automation. Robots are driven by algorithms, which have become increasingly complex. They can now operate without requiring anyone to explicitly program the mechanisms of the tasks performed. Yet, not all algorithms drive a physical machine. In fact, many algorithms are embodied in devices or applications. Once these algorithms are designed, they can be used for many tasks anywhere and at any time. For robots, the algorithms are embodied in the machines. Expanding the range of tasks performed by robots thus requires investing in robots, that is, robots are rival (Martens and Tolan 2018). This contrasts to algorithms, which are nonrival in nature. Robots are more frequently studied in empirical work because of the availability of statistics on their use. However, given the properties of robotics, studies that use robot data capture only part of the impact of automation on labor. 
In the traditional model, automation enhances the productivity of workers by complementing the tasks they perform (see, for example, Autor, Katz, and Krueger 1998; Feenstra 2008; Van Reenen 2011). Yet, for workers who perform tasks that can be substituted by automation, increasing availability of machines will lower their labor demand. Scholars have argued that new technologies tend to substitute for occupations that are intensive in routine tasks, such as assemblers, and complement nonroutine task-intensive occupations, such as managers and technical scientists (Autor, Levy, and Murnane 2003; Van Reenen 2011; Goos, Manning, and Salomons 2014; Dauth et al. 2019). This is because for routine tasks, such as monitoring, measuring, controlling, and calculating, there are wellspecified procedures which allow the task to be automated. Yet, knowing the rules that govern task procedures is not a trivial requirement. For many nonroutine tasks, such as those requiring creativity and problem-solving skills, automation is difficult and rather complements the performance of these tasks done by humans. In line with this reasoning, an analysis for Western European countries by Goos, Manning, and Salomons (2014) finds that recent technological progress has been replacing workers doing routine tasks. This is referred to as "routine-biased technological change" (RBTC). ${ }^{3}$

Predictions in the traditional model are straightforward. Firms adopt robots if it is economically feasible to do so, which is the case when profits exceed purchasing and installation costs. Therefore, substitution of robots for routine tasks is more likely in countries with higher wage levels, and there a fall in the fixed costs or the rental price will result in an increase in robot adoption (Graetz and Michaels 2018).

Recent modeling efforts by Acemoglu and Restrepo (2018) add a distinctive feature of automation: the technical ability of machines to replace workers in a widening range of tasks. They split the production process into tasks done by workers and machines. Advances in machine capabilities expand the set of tasks carried out by machines and replace labor, thus lowering labor demand.

However, robotic automation technologies also result in the creation of new tasks that cannot be done by machines, such as programming, design, and maintenance of high-tech equipment (Acemoglu and Restrepo 2019). This 'reinstatement effect' increases labor demand. The combination of tasks displaced by robots and the reinstatement of new tasks determine the reallocation of tasks between workers and machines.

Complementarity between man and machine in the Acemoglu and Restrepo (2018) model originates from two indirect effects that come on top of complementarity effects in the traditional model (Martens and Tolan 2018). The first is a price-productivity effect whereby robot adoption lowers prices of produced goods, leading the industry to expand sales and increase its demand for labor. The second is a scale-productivity effect whereby lower aggregate goods' prices enable the (local) economy to expand and thus also increase labor demand. The overall impact of robotization on labor demand then depends on whether the displacement or the complementary effects dominate. So far, empirical evidence on the aggregate employment effects from robotization are inconclusive. ${ }^{4}$

3 Autor, Levy, and Murnane (2003) examine the impact of computerization on labor demand in US industries from 1960 to 1998. They find a positive relation between the demand for nonroutine tasks and computerizing industries. Ross (2017) and De La Rica, Gortazar, and Lewandowski (2020) study the impact of RBTC on the wage premium for job tasks.

4 Acemoglu and Restrepo (2020) find that robot adoption lowers labor demand in US local labor markets. Dauth et al. (2019) argue in an analysis for Germany that workers displaced by robots reallocate to services and there is no decline in aggregate employment. In a cross-country analysis, Ghodsi et al. (2020) find that robot adoption does not significantly affect aggregate employment, although the impact varies at the industry level. 
In line with Acemoglu and Restrepo (2018), Graetz and Michaels (2018) model the production process as a continuum of tasks. Yet, Graetz and Michaels (2018) assume that products differ in the share of tasks that can be carried out by machines. Garments provide a clear example: sewing garments is a complex process that requires human intuition and dexterity, which is difficult to program. In contrast, it has proven easier to program robots to perform tasks in automobile assembly lines. ${ }^{5}$ Automation of car assembly lines has helped to reduce error rates and enhances the control of repeatable tasks. The technical feasibility of machines taking over tasks thus differs by industry.

In this expanded model, the improvement of machine capabilities may drive automation. That is, if robot adoption is constrained by the production nature of certain industries, the rental price of robots does not matter. Rather, it is an expansion in machine capabilities that will drive automation. Given that labor costs are higher in advanced economies, the relaxing of technological constraints by expanding robot capabilities will lead to higher economic incentives for robotization in advanced countries and hence stronger employment responses.

The traditional and expanded model capture the key economic mechanisms driving robot adoption and their employment effects. The PRC is an interesting case to illustrate how additional factors drive robot adoption. Wage levels in the PRC are below high-income economies, but it is the world's largest adopter of industrial robots (Cheng et al. 2019). This seems counterintuitive to the modeling of robot adoption. Yet, robot use in the PRC does coincide with rising wages and a slowdown in the growth of its working-age population. Besides labor costs, concerns over product quality and production expansion are found to influence decisions by firms in adopting robots (Cheng et al. 2019). In addition, the Government of the PRC has initiated various programs and provides subsidies that encourage the development of the robotics industry (Yang 2017, Lin 2018).

Robots may also reverse the trend to relocate fabrication activities from advanced toward lowwage countries. In an interesting contribution, Faber (2018) points out that advances in robotics will reduce production costs, no matter where the product is produced. That, he argues, will increase the attractiveness of producing domestically relative to offshoring. In effect, workers in export sectors of developing countries can be displaced by the adoption of robots, either onshore or offshore. Essentially, foreign robots act as a form of competition on the export market. Using a methodological approach similar to Acemoglu and Restrepo (2020), Faber (2018) finds that US robot adoption lowers labor demand in Mexican export-producing sectors. ${ }^{6}$

These models inform the empirical analysis in our paper. The next sections describe the methodology and data to examine the aggregate (cross-country) implications of robotization. We view this analysis as a complementary approach to the within-country comparisons in Acemoglu and Restrepo (2020), Dauth et al. (2019), and Faber (2018).

5 Clearly, some textile production can now also be nearly fully automated; an example is the adidas ${ }^{\circledR}$ Speedfactory (Faber 2018). Yet, relatively speaking, the share of tasks that robots can perform varies across industries.

6 If robots result in reshoring of a factory, this will affect all workers at the exporting plant in the developing country. Faber (2018) finds that Mexican workers in commuting zones most affected by US robots are low-educated machine operators and technicians in manufacturing and high-educated workers in managerial and professional occupations. Using the World Input-Output Tables, Krenz, Prettner, and Strulik (2018) find evidence for a positive relation between reshoring and the degree of automation. 


\section{METHODOLOGY}

To examine the relation between robot adoption and changes in the structure of the workforce, we estimate regressions similar to those in Graetz and Michaels (2018) that take the form

$$
\Delta \mathrm{L}_{\mathrm{ci}}=\beta \Delta \text { Robot adoption }_{\mathrm{ci}}+X_{c i}^{\prime} \gamma+\delta_{\mathrm{c}}+\varepsilon_{\mathrm{ci}}
$$

where $\Delta \mathrm{L}_{\mathrm{ci}}$ is the change in the employment outcome of interest in industry $i$ of country $c^{7} \Delta$ Robot adoption $_{\mathrm{ci}}$ is the change of the robot stock relative to labor input in each country-industry pair. ${ }^{8}$ Most specifications include control variables which are changes in: investment-to-value-added ratios, and (the natural logarithm of) value added. We also examine results controlling for the adoption of information and communication technologies (discussed below). $\delta_{c}$ represents country fixed effects, which in a first-difference equation are equivalent to country-specific time trends in a levels' equation. Regressions are estimated in long-run changes between 2005 and 2015 because we are interested in longer-term trends. The regressions weight industries using their 2005 employment shares within each country. This ensures that estimates reflect the importance of industries within countries, but we give equal weight to countries in the analysis (as, for example, in Graetz and Michaels 2018). We use heteroscedasticity-robust standard errors that are two-way clustered by country and industry. ${ }^{9}$ This is a conservative approach because the resulting standard errors are typically larger compared to oneway clustering by country or industry.

\section{Endogeneity Concerns and 2-Stage Least Squares Estimation}

Estimating (1) using ordinary least squares (OLS) raises several concerns about endogeneity. First, one might worry about reverse causality and omitted variable bias. For instance, industries that experience a faster growth in product demand may invest more in robots. Especially if the labor market is tight, a positive demand shock is more likely to result in investment in robots rather than an expansion of employment (Faber 2018)..$^{10}$ This is a case of reverse causality, because lower employment growth results in higher robot adoption. Also, relevant variables might be omitted from the regression analysis. For instance, Harrigan, Reshef, and Toubal (2016) find that adoption of new technologies is mediated by technically qualified workers. Second, one may worry about attenuation bias of $\beta$ in (1) due to measurement error in the variable robot adoption. Clearly, the available data on robot adoption, discussed in section IV.A, is imperfect, as it does not inform on the quality and other characteristics of robots installed. In addition, we estimate regression specifications in changes, which may worsen the signal-to-noise ratio compared to regressions of variables in levels. Due to measurement error, the variable robot adoption could be correlated with the error term $\varepsilon_{\mathrm{ci}}$ and OLS estimation of $\beta$ would be

7 The employment outcome of interest is either the average annual percentage growth rate in employment by countryindustry pair, which is estimated as $\left(\left(\ln \left(E_{\mathrm{c}} \mathrm{PP}_{\mathrm{ci}, 2015} / \mathrm{EMP}_{\mathrm{ci}, 2005}\right)\right) / 10\right) * 100$, or it is the change in the task-specific employment share by country-industry pair, measured as the share in 2015 minus the share in 2005.

8 Robot adoption is defined as the number of robots installed per thousand persons employed. We follow Graetz and Michaels (2018) and use the percentile rank of the change in robot adoption as our main explanatory variable. This is further elaborated upon in Section IV.A.

9 We implement Stata's 'ivreg2' command for OLS and 2SLS regressions. Two-way clustered standard errors are robust to arbitrary heteroscedasticity and intra-group correlation within each of the two (non-nested) categories "country" and "industry" (Cameron, Gelbach, and Miller 2012). This allows for robust inference, for example, if errors are correlated within countries (e.g., due to unobserved country-specific policies) and have separate correlation structures within industries (e.g., due to technology shocks).

10 In his analysis of the Mexican labor market, Faber (2018) points out that a positive demand shock due to the North American Free Trade Agreement may have put upward pressure on industries or local labor markets to adopt robots if they had less room to expand employment. 
biased downward. Finally, industries that adopt robots may differ from other industries in nonrandom ways, which would also bias the coefficient if not appropriately controlled for. Hence, the direction of bias in $\beta$ is not clear a priori, although the previous literature suggests that a downward bias in OLS is more likely (e.g., Graetz and Michaels 2018).

In an attempt to address these endogeneity concerns, we use two industry-specific instruments introduced by Graetz and Michaels (2018) and estimate (1) using 2SLS." The first instrument measures the share of each industry's labor input that is replaceable by robots. This instrument is constructed using information on the tasks performed by robots (IFR 2012). As discussed above, the extent of robotization for each task could be endogenous to industry conditions. Therefore, Graetz and Michaels (2018) use information on US occupations in each industry from the 1980 census, which dates back before the rise of robots. Occupations are defined as 'replaceable' if (part of) their tasks could have been replaced by robots in 2012. They then compute the fraction of hours worked in each industry in 1980 that was performed by occupations that subsequently became more prone to replacement by robots. This instrument is not without limitations: it is based on data from the US and labor shares might therefore be different if constructed using data from other countries. ${ }^{12}$

The second instrument is motivated by rapid improvements in the ability of robotic arms to perform 'reaching and handling' tasks. It measures the prevalence of occupations in each industry that require reaching and handling tasks compared to other physical demands in 1980, prior to robot adoption. Robotic arms are a salient characteristic of robots, and much technological advances are linked to the development of these robotic arms (Graetz and Michaels 2018). It is therefore more likely that robotic arms are a technological characteristic of robots, less driven by the demand side (due to industries' task requirements), which could reflect reverse causality. This instrument is constructed using the extent to which occupations in each US industry require reaching and handling tasks compared to other physical tasks in $1980 .{ }^{13}$ Similar limitations as to the first instrument apply here, but one may argue that this instrument is less likely to violate the exclusion restriction.

Clearly, neither instrument can guarantee to resolve all endogeneity concerns. Both instruments reflect variation across industries in the share of tasks that are potentially replaceable by robots, which may correlate with other changes over time. Nevertheless, the instruments are helpful to contrast OLS with 2 SLS results.

1 The instruments are computed for two-digit industries in the ISIC Revision 3 classification, which matches with the industry information on robot stocks and occupational employment shares presented in section IV.A. Note that the instruments do not vary across countries but only across industries.

12 Also note the replacement values are an upper bound because occupations are considered to be replaceable even if only part of their work can be replaced by robots.

13 Information on the task content of occupations is taken from the Dictionary of Occupational Titles. 


\section{DATA AND DESCRIPTIVE ANALYSIS}

We first describe the data on robots and occupations in section IV.A. Descriptive statistics are presented in section IV.B.

\section{A. Occupations and Robots}

We combine two datasets with information on occupations and robot purchases. The first dataset with occupational employment by country-industry originates from Reijnders and de Vries (2018) and was updated by Buckley et al. (2020). The data is constructed using detailed survey and census data from statistical offices for the period 2000-2015. The sources used in constructing this dataset closely align with those from other studies. ${ }^{14}$ The dataset provides employment for 13 occupational groupings by country-industry pairs. It covers 40 economies, namely the 27 members of the European Union (per January 2007); Australia; Brazil; Canada; India; Indonesia; Japan; Mexico; the PRC; Russian Federation; the Republic of Korea; Taipei,China; Turkey; and the US. For each of these economies, occupational employment shares by 35 ISIC Revision 3.1 industries that cover the overall economy are distinguished. They include 14 two-digit manufacturing industries (such as textile manufacturing and electronics manufacturing), as well as agriculture, mining, construction, utilities, finance, business services, personal services, trade and transport services, and public service industries. The dataset thus has dimensions of 13 occupational groupings $x 35$ industries $x 40$ economies $x 16$ years. Occupation data is intrinsically not exactly comparable across economies, and in practice will also vary due to differences in the type of sources and national data collection practices. Intertemporal changes within countryindustries are likely more consistent because Reijnders and de Vries (2018) use data from the same national source for each economy. Our empirical analysis exploits this within-country variation.

We examine the impact of robot adoption on tasks, which we distinguish into routine versus nonroutine and manual versus analytic tasks. Our measurement strategy is to infer the impact of robot adoption on tasks from data on the occupational structure of the workforce. The distinction between occupations with different task intensities is based on the so-called Routine Task Intensity (RTI) index developed by Autor, Levy, and Murnane (2003) and mapped into the International Standard Classification of Occupations (ISCO 88) by Goos, Manning, and Salomons (2014). Table 1 provides the allocation of occupational groupings to tasks.

The second database includes deliveries of industrial robots by country-industry from the International Federation of Robotics (IFR). ${ }^{15}$ The IFR provides country data on the number of industrial robots delivered from 1993 onward. Yet coverage varies and the breakdown of robot investment by country-industry is only consistently available for most countries after 2004. In addition, robot investments increased rapidly during the 2000s. We therefore build the dataset using information for all available years but focus on the period 2005-2015 in the empirical analysis. ${ }^{16}$

14 For example, for the US, the sources are the 2000 Census and the annual American Community Surveys. These sources are also used in Autor (2015). Data for European countries are from the harmonized individual level European Union Labour Force Surveys, which are also used in Goos, Manning, and Salomons (2014).

15 Purchases of service robots are only available for recent years and few countries, which limits studying the impact on task demand of robot adoption in the service sectors.

16 Program code to replicate the analysis is available from the authors upon request. 
Table 1: Mapping Occupations to Tasks

\begin{tabular}{lll}
\hline & \multicolumn{1}{c}{ Routine } & \multicolumn{1}{c}{ Nonroutine } \\
\hline Manual & $\begin{array}{l}\text { Production workers (71-74, 81-82, 93) } \\
\text { Agricultural workers (61-62, 92) } \\
\text { Others (01, 999) }\end{array}$ & $\begin{array}{l}\text { Support services workers (51, 910, 912-916) } \\
\text { Drivers (83) }\end{array}$ \\
\hline Analytic & Administrative workers (41-42) & \\
& & Legislators (11) \\
& Managers (12-13) \\
& Engineers (21, 31) \\
& Health professionals (22, 32) \\
& Teaching professionals (23, 33) \\
& Other professionals (24, 34) \\
& Sales workers (52, 911) \\
\hline
\end{tabular}

Note: Numbers in brackets refer to International Standard Classification of Occupations codes (ISCO 88).

Sources: Mapping of 13 occupations from Reijnders and de Vries (2018) to four different groups based on Autor, Levy, and Murnane (2003) and Goos, Manning, and Salomons (2014).

We use the perpetual inventory method to build robot stocks, assuming a depreciation rate of $10 \%$ as in Graetz and Michaels (2018). ${ }^{17}$ We then define 'robot densification' or simply 'robot adoption' as the robot stock per thousand persons employed. We examine changes in robot adoption over time. The distribution of changes in robot adoption for the country-industries included in our analysis has mostly either zero or small positive values, with a long right tail. Analyzing raw changes in robot density is therefore not recommendable and we use the percentile of changes in robot adoption (based on the employment-weighted distribution of changes) as in Graetz and Michaels (2018). ${ }^{18}$

We match the data on robot adoption with occupational employment. ${ }^{19}$ The 19 sectors that are matched are 14 manufacturing industries, agriculture, mining, utilities, construction, and 'education and R\&D'. The (unweighted) average employment share of these sectors in the total economy across the sampled economies is 46\% and 39\% in 2000 and 2015, respectively. The share varies across levels of development. It is about a quarter of the workforce in advanced countries such as Denmark, the Netherlands, and the US throughout the sample period. It is over $50 \%$ of total persons employed in industrializers such as the PRC, Turkey, and Poland.

17 The perpetual inventory method to build robot stocks is: $R_{c i, t}=(1-d){ }^{*} R S_{c i, t-1}+R D_{c i, t}$, where $R S$ is the robot stock of industry $i$ in country $c$ at time $t$; RD are robot deliveries, and $\mathrm{d}$ is the depreciation rate. Our main results are robust to building the robot stock using a 5\% and a 15\% depreciation rate.

18 We follow Graetz and Michaels (2018) and calculate within-country employment-weighted distributions of changes in robot adoption between 2005 and 2015. We use the Stata code that Graetz and Michaels (2018) made available at https://dataverse.harvard.edu/dataset.xhtml?persistentld=doi:10.7910/DVN/5JWBXU. Specifically, we denote robot adoption by $\mathrm{RA}_{\mathrm{ci}, \mathrm{t}}=\mathrm{RS}_{\mathrm{ci}, \mathrm{t}} / \mathrm{EMP}_{\mathrm{ci}, \mathrm{t}}$, that is, the robot stock per thousand persons employed in industry $i$ of country $c$. We denote $\mathrm{ws}_{\mathrm{c}}$ the weighted change in robot adoption of country $c$, which is the summation of changes in robot adoption by industry $i$ weighted by their employment shares. The change in robot adoption net of the weighted change in robot adoption is $\Delta \mathrm{RA}_{\mathrm{ci}}=\left(\mathrm{RA}_{\mathrm{ci}, \mathrm{t}}-\mathrm{RA}_{\mathrm{ci}, \mathrm{t}-1}\right)-\mathrm{ws}_{\mathrm{c}}$. We then calculate the percentile rank of the change in robot adoption ( $\left.\Delta \mathrm{RA} \mathrm{A}_{\mathrm{ci}}\right)$ and use this variable in the regression analysis. The use of percentiles is common in the economics literature and helpful when the data is skewed, see, for example, Autor, Levy, and Murnane (2003).

19 After matching the datasets, we have data for 37 economies and 19 sectors, with missing data for a few country-industry pairs. High-income economies include the 'old' EU15 countries, western offshoots, and high-income East Asian economies, namely Australia; Austria; Belgium; Canada; Denmark; Finland; France; Germany; Greece; Ireland; Italy; Japan; Malta, the Netherlands; Portugal; the Republic of Korea; Spain; Sweden; Taipei,China; the United Kingdom; and the US. EMTEs are the others, namely Brazil, Czech Republic, Estonia, Hungary, Indonesia, India, Lithuania, Latvia, Mexico, Poland, the PRC, Romania, Russian Federation, Slovakia, Slovenia, and Turkey. 
In most regression specifications, we control for changes in the investment-to-value-added ratios, and (the natural logarithm of) value added. ${ }^{20}$ Although robots are a visible and much discussed form of automation, computers and other digital technologies impact jobs as well. Information and communication technologies (ICTs) have been found to be skill biased, raising the productivity of highskilled workers and lowering demand for low-skilled workers (Feenstra 2008; Michaels, Natraj, and Van Reenen 2014). In contrast, robots are part of recent innovations and considered routine biased, as they substitute for workers performing routine manual tasks (Goos, Manning, and Salomons 2014). These routine tasks are often performed by workers with a middling level of education, such as fabrication jobs involving repetitive production tasks (Autor 2015). We therefore expect a direct effect of robot adoption on the demand for routine manual task-intensive occupations independent of ICT investment.

To control for ICT adoption, we use data from the EU KLEMS Release 2019 for gross fixed capital formation in computing and communication equipment (Stehrer et al. 2019). These ICT investments are expressed as a share in total investment. Changes in the ICT investment share are included in the analysis, also in the form of the percentile of changes in ICT adoption (based on the employment-weighted distribution of changes).

\section{B. Descriptive Analysis}

Table 2 shows descriptive statistics of our key dependent and explanatory variables. The top rows show changes in employment shares for occupations by task intensity. On average, the routine (manual) employment share declined by 4 percentage points between 2005 and 2015 . This trend is observed in 35 out of 37 economies, but the decline in the routine share differs across economies and industries. This can be seen in Appendix Figures 1 and 2, which depict the changes in employment shares for our four occupational groupings by country and industry, respectively. The decline in routine manual occupations is mirrored by the rise of nonroutine analytic jobs, which increased by 4 percentage points on average. ${ }^{21}$ The comparability of the shifts in routine manual and nonroutine analytic occupations across our sample of high-income economies and EMTEs makes it likely that a common set of forces contributes to shared developments in labor markets. The prime suspect is automation (Autor 2015). At the same time, variation in country-specific experiences underscores that no common cause will explain the full diversity of labor market developments across these economies.

The average robot stock per thousand persons employed more than doubled from 2.23 in 2005 to 4.98 in 2015 . The standard deviation of robotization reveals substantial variation in robotization across countries and industries. Most of this variation stems from cross-industry differences within economies as opposed to variation between economies. ${ }^{22}$ More robots were installed in all economies, with the number of robots per thousand persons employed surging in

20 This data is obtained from the World Input-Output Database 2016 release (Timmer et al. 2015). The first control variable, investment-to value-added ratios may be subject to concerns about multi-collinearity as robots are part of physical capital investment. We explored the share of robot investment in overall investment by using turnover-based prices of robots for the US provided in IFR (2012). The number of robot times their unit price gives a rough approximation of nominal investment. Our estimates suggest that the share of robot investment in total investment is small, typically not exceeding $1 \%$. The first differences of our data for robot adoption and investment-to-value-added ratios are only loosely correlated, with a correlation coefficient of -0.06 .

${ }^{21}$ Changes in the shares of routine analytic and nonroutine manual jobs are typically smaller and we observe substantial variation across economies (see Appendix Figure 1).

22 The standard deviation of the robot stock per thousand employed between economies is 8.06 in 2015 . In comparison, the standard deviation of robot adoption within economies is 21.06 in 2015 . Those are calculated, respectively, as the standard deviations of country means $\bar{x}_{c}$ and of their deviations $x_{c i}-\bar{x}_{c}+\overline{\bar{x}}$, where $\mathrm{x}$ indicates robot adoption and $\overline{\bar{x}}$ is its global average. 
Germany, Japan, and the Republic of Korea (see Appendix Figure 3) ${ }^{23}$ High robot density is observed in machinery, electronics, and automotive (see Appendix Figure 4). For industries that produce chemicals and metal products, we also observe an increase in robot density, albeit starting from low levels.

Appendix Figure 5 shows the number of robots per 1,000 persons employed by industry in the PRC and Germany for 2015. This figure helps clarify the lower level of robots per thousand persons employed in the PRC. For example, in 2015, the number of robots installed in the PRC's automotive industry was about 50,000, which compares to a slightly lower number of around 48,500 robots in that industry for Germany. Yet, in 2015, the number of persons employed in automotive is about 6.8 million in the PRC compared to 965 thousand in Germany, so a factor 7 difference in the size of the workforce in that industry. Hence, the number of robots installed per thousand persons employed is about 7 in the PRC compared to 50 in Germany.

Table 2 also provides descriptive statistics for the instruments and control variables. The instruments replaceable tasks and reaching and handling tasks are positively correlated, but different. ${ }^{24}$ For example, the highest share of replaceable tasks is observed in automotive and metal manufacturing, whereas the extent of reaching and handlings tasks is highest in textile and food manufacturing.

Table 2: Descriptive Statistics

\begin{tabular}{|c|c|c|c|c|c|}
\hline & Obs & Mean & SD & p5 & p95 \\
\hline \multicolumn{6}{|l|}{ Dependent variables } \\
\hline Employment growth (average annual, in \%) & 700 & -0.78 & 3.41 & -6.0 & 3.9 \\
\hline$\Delta$ Routine employment share & 700 & -0.04 & 0.10 & -0.2 & 0.1 \\
\hline$\Delta$ Routine manual employment share & 700 & -0.04 & 0.12 & -0.2 & 0.1 \\
\hline$\Delta$ Routine analytic employment share & 700 & -0.00 & 0.05 & -0.1 & 0.1 \\
\hline$\Delta$ Nonroutine manual employment share & 700 & -0.00 & 0.06 & -0.1 & 0.1 \\
\hline$\Delta$ Nonroutine analytic employment share & 700 & 0.04 & 0.10 & -0.1 & 0.2 \\
\hline \multicolumn{6}{|l|}{ Independent variables } \\
\hline Percentile of changes in robot adoption & 700 & 0.50 & 0.29 & 0.0 & 1.0 \\
\hline Robot adoption, 2005 & 700 & 2.23 & 10.17 & 0.0 & 10.5 \\
\hline Robot adoption, 2015 & 700 & 4.98 & 22.54 & 0.0 & 21.1 \\
\hline$\Delta$ Investment-to-value-added ratio & 700 & 0.02 & 0.69 & -0.2 & 0.2 \\
\hline
\end{tabular}

23 For Japan, reported deliveries and stocks of robots changed over time due to a reclassification of machines as robots (Graetz and Michaels, 2018). In section V.B, we show that the main results are robust to dropping Japan from the sample.

24 Note the instruments are measured by industry based on data for the US (see section IV.A) and matched to the countryindustry pairs. 
Table 2 continued

\begin{tabular}{|c|c|c|c|c|c|}
\hline & Obs & Mean & SD & p5 & p95 \\
\hline$\Delta$ (natural logarithm of) value added & 700 & 0.21 & 0.60 & -0.7 & 1.1 \\
\hline Percentile of changes in information technology adoption & 277 & 0.51 & 0.29 & 0.0 & 1.0 \\
\hline $\begin{array}{l}\text { Percentile of changes in communication technology } \\
\text { adoption }\end{array}$ & 277 & 0.50 & 0.30 & 0.0 & 1.0 \\
\hline IV: Reaching and handling tasks & 700 & 0.45 & 0.05 & 0.3 & 0.5 \\
\hline IV: Replaceable tasks & 700 & 0.25 & 0.12 & 0.0 & 0.4 \\
\hline
\end{tabular}

IV = instrumental variable.

Notes: A ' $\Delta$ ' in front of a variable refers to the change between 2005 and 2015. For variable descriptions, see section IV.A. In the columns, 'obs' refers to the number of observations, SD the standard deviation, $\mathrm{p} 5$ the 5 th percentile, and $\mathrm{p} 95$ the 95 th percentile.

Source: Authors' calculations.

Figure 1 plots the change in the routine employment share against measures of increased robot use. In subfigure (a), we plot the percentile of the change in robot density net of country trends on the horizontal axis, as well as the fitted regression line. The slope is negative and statistically significant. The distribution of data points around the fitted line suggest that the relationship between the routine share and the percentile of robot densification is well approximated by a linear functional form. In subfigure (b), we instead plot changes in robot density on the horizontal axis (again net of country trends), together with the fitted line. Here a linear functional form (though also negative and significant at conventional levels) seems much less adequate, and the estimated slope appears sensitive to several outlying observations near the top of the distribution of robot densification. Thus, following Graetz and Michaels (2018), in the regression analysis we will use the percentile of changes in robot densification.

Figure 1: Robots and the Routine Employment Share
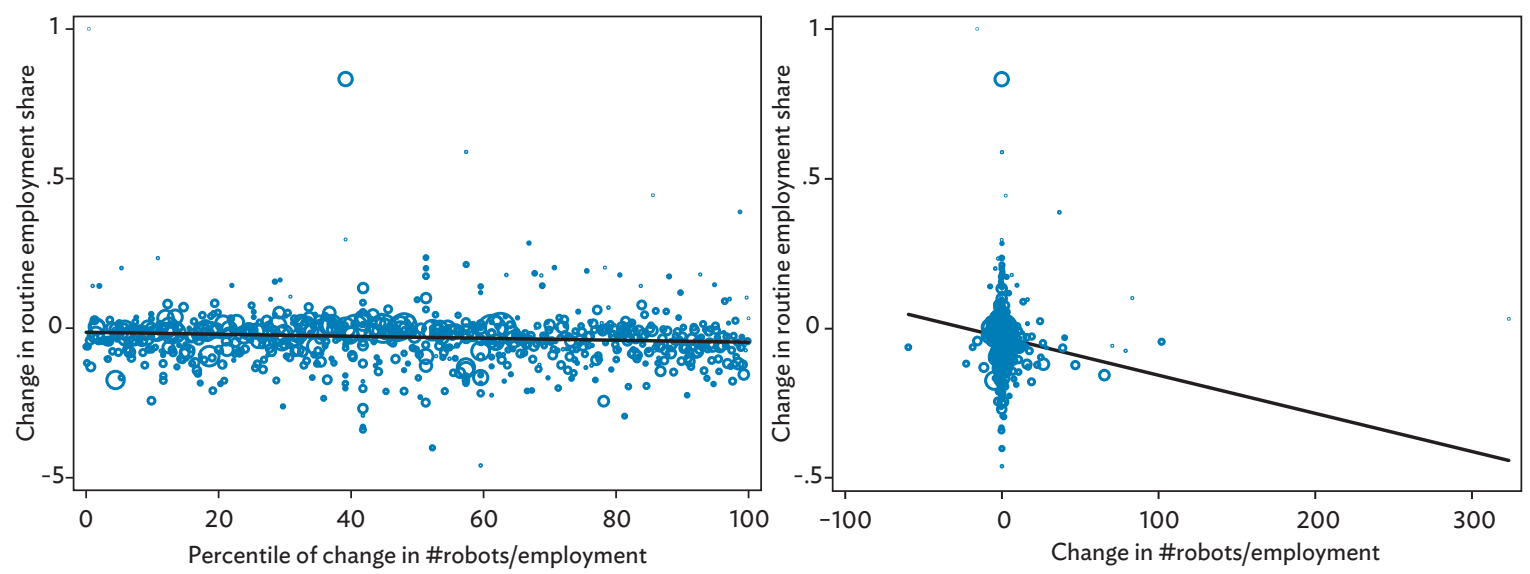

Notes: Observations are country-industry cells. The size of each circle corresponds to an industry's 2005 within-country employment share. Vertical axis displays the change in the routine employment share between 2005 and 2015. Horizontal axis of panel (a) shows the percentile of changes in robot adoption (based on the employment-weighted distribution of changes), see section IV.A. Panel (b) changes in robot adoption (based on the employment-weighted distribution of changes). Fitted regression lines are shown. Coefficients (standard errors) of the linear fit are respectively -0.00033 (0.00010) and -0.0013 (0.0004).

Source: Authors' calculations. 
Panel (a) of Figure 2 shows a descriptive relation between robot adoption and industry average changes in the routine employment share between 2005 and 2015 (see Appendix Table 1 for the industry descriptions). We observe a (slightly) stronger reduction in the routine share for industries that invested more in robots. Sectors such as paper and utilities experienced a decline in the share of routine jobs with only a relatively small increase in robotization. In manufacturing industries such as machinery, electronics, and automotive, we observe a decrease in the share of routine jobs. These industries are also among the ones with the strongest increase in robot adoption. Panels (b) and (c) suggest both instruments are good predictors, as industries with a higher share of replaceable tasks or those more intensive in reaching and handling tasks have installed more robots compared to others. The next section formally tests these relationships.

\section{Figure 2: Cross-Industry Variation in Instrumental Variables and Changes in the Routine Employment Share}
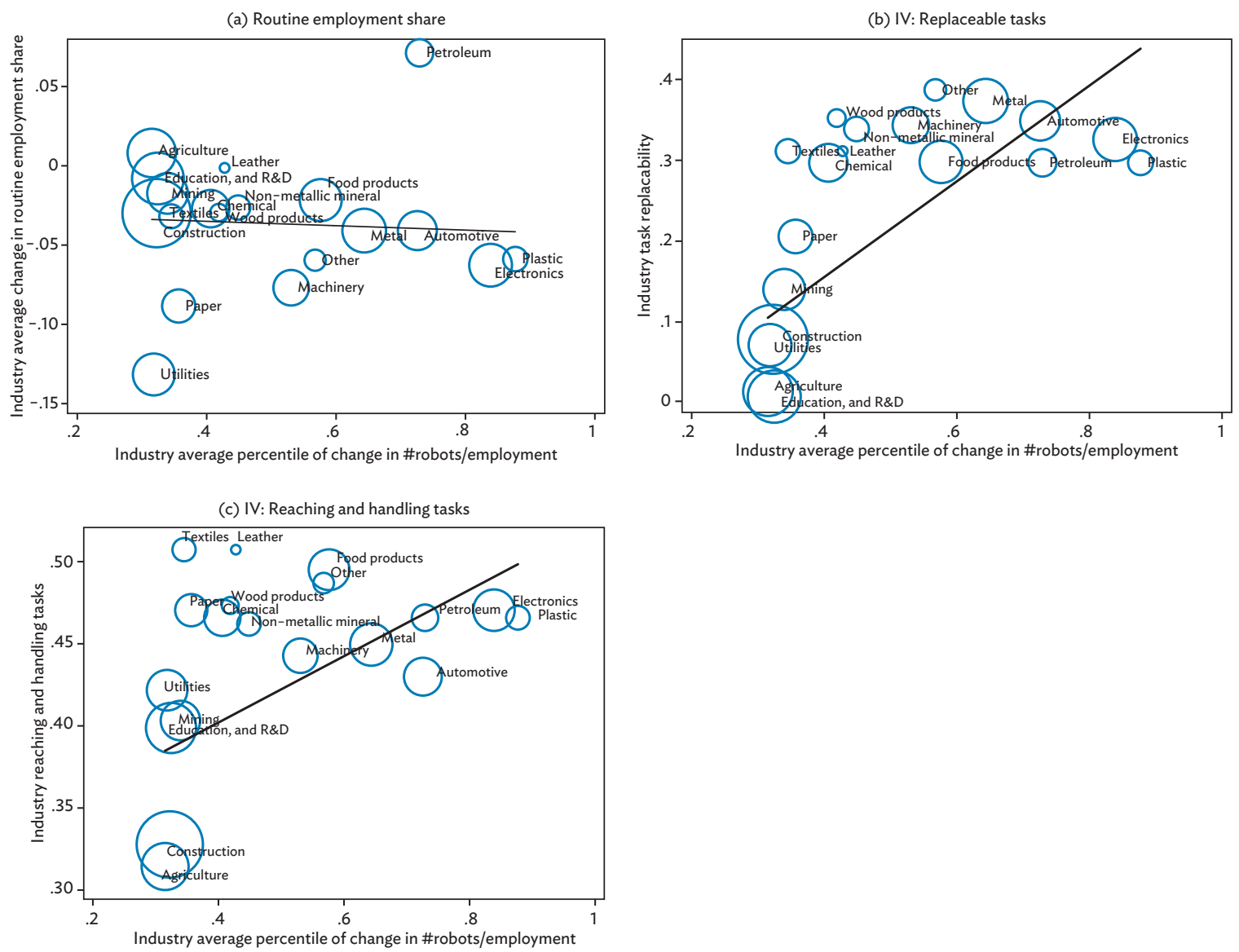

IV = instrumental variable, $R \& D=$ research and development.

Notes: On the horizontal axis is the (unweighted) average percentile of changes in robot adoption by industry. In panel (a), the vertical axis shows the industry (unweighted) average change in the routine employment share between 2005 and 2015. The coefficient (standard error) of the linear fit in panel (a) is $-0.013(0.007)$. The vertical axis of panels (b) and (c) show the values for the instruments, coefficients (standard errors) of the linear fit are respectively 0.59(0.11) and 0.20(0.07).

Source: Authors' calculations. 


\section{ECONOMETRIC RESULTS}

We present our main results from OLS and 2SLS regressions in section V.A. We find that robot adoption relates to a decline in the employment share of occupations with a high content of manual routine tasks. In section V.B, we present several extensions and robustness checks. We first document that results appear neither driven by specific sectors or economies nor spurious industry trends. We then exploit heterogeneity in task intensity across (blue-collar) production workers and find that robot adoption relates to declining demand for occupations that are more intensive in routine tasks. Finally, we explore whether global developments in robotization impact labor demand in EMTEs.

\section{A. Main Ordinary Least Squares and 2-Stage Least Squares Results}

Our main regression results are summarized in Table 3, with OLS results in panel (a) and 2SLS results in panel (b). We start the analysis by regressing the average annual percentage growth of employment on robot adoption. Country fixed effects are included; thus, coefficients are identified from variation across industries. We use a conservative two-way clustering of standard errors at the country and industry level. Column 1 of Table 3 indicates that robot adoption is negatively correlated with the average growth rate of employment between 2005 and 2015. However, this relationship is not statistically different from zero. It suggests robot adoption is not labor replacing, which was also observed by Graetz and Michaels (2018). Our finding indicates this result holds in a larger country sample.

In column (2) of Table 3, we examine the relation between robot adoption and the share of routine jobs. We find that increased robot use contributes to a decline in the routine employment share. To assess the economic magnitude, consider the difference between an industry with a median trend in robot adoption and an industry with no robot adoption, which equals $0.5 \times-0.047=-0.02$ in the OLS regression. This difference amounts to about 59\% of the average change in the routine employment share (which is -0.04 , see Table 2). While this indicates a sizable impact of robots on occupational shifts, the R-squared of $2 \%$ in column (2) where country fixed effects are partialled out, indicates that many other factors than robot adoption affect changes in the share of routine jobs. The coefficient more than doubles in the 2SLS regression, where we use the share of replaceable tasks in industries as an instrument (panel [b], column [2]). The instrument is positively and statistically significantly correlated with robot adoption in the first stage, which is reported in column (4) of panel (b). Identification is strong, with the Cragg-Donald Wald F statistic (268.53, assuming i.i.d. errors) and the Kleibergen-Paap F-statistic (23.42) surpassing the 10\% critical value (16.38). Under-identification is rejected at the $5 \%$ level of statistical significance. The considerable increase in the estimated second stage coefficient for robot adoption, when compared to OLS results, may reflect measurement error in our main explanatory variable: an increase in the noise-to-signal ratio in robot adoption will bias OLS estimates toward zero. Moreover, the increase in the coefficient in 2SLS estimates may reflect that our instrument for robot adoption only varies across industries and that global industry trends impact changes in routine employment shares (see subsection V.B below). Using 'reaching and handling' tasks as an instrument gives similar results, although more prone to weak identification concerns (see Appendix Table 2). 


\section{Table 3: Baseline Regression Results of Employment Growth and Change in Routine Employment Share}

\begin{tabular}{|c|c|c|c|c|}
\hline & (1) & $\begin{array}{c}(2) \\
\Delta \text { Routine } \\
\text { Employment } \\
\text { Share }\end{array}$ & $\begin{array}{c}\text { (3) } \\
\Delta \text { Routine } \\
\text { Employment } \\
\text { Share }\end{array}$ & $\begin{array}{c}\text { (4) } \\
\text { Percentile of } \\
\text { Changes in } \\
\text { Robot Adoption }\end{array}$ \\
\hline \multicolumn{5}{|l|}{ (a) OLS } \\
\hline Percentile of changes in robot adoption & $\begin{array}{r}-0.354 \\
(0.73)\end{array}$ & $\begin{array}{r}-0.047^{* * *} \\
(0.02)\end{array}$ & $\begin{array}{r}-0.055^{* * *} \\
(0.02)\end{array}$ & \\
\hline $\begin{array}{l}\text { Percentile of changes in robot adoption } x \\
\text { dummy EMTE }\end{array}$ & & & $\begin{array}{r}0.040^{* * *} \\
(0.02)\end{array}$ & \\
\hline$R^{2}$ & 0.001 & 0.025 & 0.028 & \\
\hline Observations & 700 & 700 & 700 & \\
\hline Number of economies & 37 & 37 & 37 & 37 \\
\hline \multicolumn{5}{|l|}{ (b) 2SLS (IV: Replaceable tasks) } \\
\hline Percentile of changes in robot adoption & $\begin{array}{l}-2.714 \\
(3.03)\end{array}$ & $\begin{array}{r}-0.120^{* *} \\
(0.05)\end{array}$ & $\begin{array}{r}-0.156^{* *} \\
(0.06)\end{array}$ & \\
\hline $\begin{array}{l}\text { Percentile of changes in robot adoption } x \\
\text { dummy EMTE }\end{array}$ & & & $\begin{array}{l}0.136^{* *} \\
(0.06)\end{array}$ & \\
\hline Replaceable tasks & & & & $\begin{array}{r}0.892^{* * *} \\
(0.18)\end{array}$ \\
\hline Cragg-Donald Wald F statistic & & & & 268.53 \\
\hline Kleibergen-Paap F-statistic & & & & 23.42 \\
\hline $\begin{array}{l}\text { Kleibergen-Paap under identification test } \\
\text { ( } p \text {-value) }\end{array}$ & & & & 0.013 \\
\hline$R^{2}$ & -0.052 & -0.027 & -0.053 & \\
\hline Observations & 700 & 700 & 700 & 700 \\
\hline Number of economies & 37 & 37 & 37 & 37 \\
\hline
\end{tabular}

2SLS = two-stage least squares, $\mathrm{EMTE}=$ emerging market and transition economy, $\mathrm{IV}=$ instrumental variable, OLS = ordinary least squares. Notes: Robust standard errors in parentheses. Multi-way clustering by country and industry. The dependent variable employment growth in column (1) is the average annual percentage growth in employment for the period 2005-2015. The dependent variable in columns (2)-(3) is the change in the routine employment share between 2005 and 2015. Column (4) reports the first stage for 2SLS estimation. The share of replaceable tasks in an industry is used as an instrument for robot adoption. Regressions include the change in the investment-to-valueadded ratio and the change in (the log of) value added between 2005 and 2015 as control variables. Country fixed effects are included in all regressions and partialled out in the reported $R^{2} .{ }^{* *} p<0.01,{ }^{* *} p<0.05,{ }^{*} p<0.1$.

Source: Authors' calculations. 
An advantage of our dataset is the broad economy coverage, including various emerging market and (post-) transition economies. In column (3) of Table 3, we differentiate the relation between robot adoption and routine shares across high-income economies and EMTEs. ${ }^{25}$ We do so by interacting a dummy variable for EMTEs with robot adoption. ${ }^{26}$ The relationship between robot adoption and declining routine shares appears to mainly occur in high-income economies: for both, the OLS and 2SLS regressions, the negative overall coefficient estimate for robot adoption in column (3) is almost equal in size to the positive interaction term with the EMTE dummy, indicating that the effect of robot adoption is essentially nullified in those economies. ${ }^{27}$ Since technical constraints to robots replacing tasks are more likely to bind for firms in high-wage advanced economies, improvements in robot capabilities might account for the larger employment response in advanced economies compared to EMTEs.

Additionally, our dataset allows us to further disaggregate routine and nonroutine employment shares into manual and analytic task-intensive occupations. Results are reported in Table 4, again with OLS results in panel (a) and $2 \mathrm{SLS}$ results in panel $(\mathrm{b}) .{ }^{28}$ We find that the negative relation between robot adoption and routine employment shares is exclusively driven by manual routine jobs: the estimates in column (1) of Table 4 essentially mimic those of column (2) in Table 3, while no relationship can be found between robot adoption and analytic routine employment shares (Table 4, column 2 ). It thus appears robots are better suited to substitute for routine manual tasks due to the ability of robots to manipulate objects. Conversely, the share of nonroutine analytic occupations positively relates to robot adoption (column 4). This is consistent with the intuition that nonroutine analytic tasks are complemented by robots in production (Autor 2015). No relevant relationship is observed between robot adoption and changes in the manual nonroutine employment share (column 3).

25 Given the number of robots installed in the PRC, it might be less appropriate to classify it as an EMTE. To check for robustness of reported results, we omitted the PRC from the sample and reclassified it as a non-EMTE. This did not alter the results (available upon request).

26 In the reported 2SLS regressions, we only instrument robot adoption but not the interaction. We additionally estimated 2SLS regressions with the interaction instrumented, which required interaction of our instrument with an EMTE dummy in the first stage. Results, which are available upon request, were quantitatively and qualitatively similar to those reported, but more prone to weak identification concerns.

27 OLS and 2SLS estimates of $\beta$ are not statistically significantly different from zero when estimating equation (1) for EMTEs only. Results are available upon request.

28 Note that first-stage results for the 2SLS case are the same as in Table 3. 
Table 4: Robot Adoption and Changes in Employment Shares by Task Type

\begin{tabular}{|c|c|c|c|c|}
\hline & $\begin{array}{c}(1) \\
\Delta \text { Routine } \\
\text { Manual } \\
\text { Employment } \\
\text { Share }\end{array}$ & $\begin{array}{c}\text { (2) } \\
\Delta \text { Routine } \\
\text { Analytic } \\
\text { Employment } \\
\text { Share }\end{array}$ & $\begin{array}{c}\text { (3) } \\
\Delta \text { Nonroutine } \\
\text { Manual } \\
\text { Employment } \\
\text { Share }\end{array}$ & $\begin{array}{c}(4) \\
\Delta \text { Nonroutine } \\
\text { Analytic } \\
\text { Employment } \\
\text { Share }\end{array}$ \\
\hline \multicolumn{5}{|l|}{ (a) OLS } \\
\hline \multirow[t]{2}{*}{ Percentile of changes in robot adoption } & $-0.049^{* * *}$ & 0.002 & -0.008 & $0.055^{* * *}$ \\
\hline & $(0.02)$ & $(0.00)$ & $(0.01)$ & $(0.02)$ \\
\hline \multirow[t]{2}{*}{$\Delta$ Investment-to-value-added ratio } & $0.003^{* * *}$ & 0.001 & -0.001 & $-0.003^{* * *}$ \\
\hline & $(0.00)$ & $(0.00)$ & $(0.00)$ & $(0.00)$ \\
\hline \multirow[t]{2}{*}{$\Delta$ (natural logarithm of) value added } & 0.005 & 0.002 & 0.004 & -0.009 \\
\hline & $(0.01)$ & $(0.00)$ & $(0.00)$ & $(0.01)$ \\
\hline $\mathrm{R}^{2}$ & 0.024 & 0.003 & 0.007 & 0.031 \\
\hline Observations & 700 & 700 & 700 & 700 \\
\hline Number of economies & 37 & 37 & 37 & 37 \\
\hline \multicolumn{5}{|l|}{ (b) 2SLS (IV: Replaceable tasks) } \\
\hline \multirow[t]{2}{*}{ Percentile of changes in robot adoption } & $-0.119^{* *}$ & -0.003 & -0.032 & $0.152^{* * *}$ \\
\hline & $(0.05)$ & $(0.01)$ & $(0.02)$ & $(0.05)$ \\
\hline \multirow[t]{2}{*}{$\Delta$ Investment-to-value-added ratio } & $0.004^{* * *}$ & 0.001 & -0.001 & $-0.004^{* * *}$ \\
\hline & $(0.00)$ & $(0.00)$ & $(0.00)$ & $(0.00)$ \\
\hline \multirow[t]{2}{*}{$\Delta$ (natural logarithm of) value added } & 0.012 & 0.003 & 0.006 & $-0.019^{* *}$ \\
\hline & $(0.01)$ & $(0.00)$ & $(0.01)$ & $(0.01)$ \\
\hline $\mathrm{R}^{2}$ & -0.020 & 0.001 & -0.021 & -0.059 \\
\hline Observations & 700 & 700 & 700 & 700 \\
\hline Number of economies & 37 & 37 & 37 & 37 \\
\hline
\end{tabular}

$2 \mathrm{SLS}=$ two-stage least squares, IV = instrumental variable, $\mathrm{OLS}=$ ordinary least squares.

Notes: Robust standard errors in parentheses. Multi-way clustering by country and industry. The dependent variable is the change in the respective employment share between 2005 and 2015. The share of replaceable tasks in an industry is used as an instrument for robot adoption. Country fixed effects are included in all regressions and partialled out in the reported $R^{2} .{ }^{* *} p<0.01,{ }^{* *} p<0.05,{ }^{*} p<0.1$.

Source: Authors' calculations.

\section{B. Robustness and Extensions}

We performed several robustness checks. These are summarized in subsection V.B.1. The other subsections focus on aspects considered relevant to better understand the relation between robotization and routine employment shares and to motivate future research in this area. Subsection V.B.2 examines the relation between robot adoption across production occupations that differ in task intensity. Subsection V.B.3 examines whether the results are driven by longer-term industry trends. Finally, subsection V.B.4 explores the role of global industry trends in robot adoption for driving country-industry changes in employment shares. 


\section{Robustness and Heterogeneity}

We first examine regression results when adding ICT investment to the analysis. This is because computers seem particularly suited to substitute for analytic tasks and the development of computer and communication equipment is not independent of robot adoption, such that omitting ICT may bias the coefficient for robot adoption. Including variables for computer and communication investment leads to a considerable decline in the sample to 277 observations because the EU KLEMS dataset does not report ICT investment by industry for many EMTEs. The estimated coefficient for the relation between robot adoption and routine employment shares is smaller but remains negative and statistically significant in the OLS and IV regressions (see column 1 of Appendix Table 3). ${ }^{29}$

To avoid results being driven by certain economies, we inspect the pattern of OLS residuals (depicted in Appendix Figure 6). Furthermore, we look at the distribution of economy-specific parameter estimates, which we obtain by interacting robot adoption with a matrix of economy dummy variables in our main OLS specification (see Appendix Figure 7). There is a cluster of high fitted values for Ireland (Appendix Figure 6, panel [a]) and two residuals from Romania and Sweden obtain a relatively high leverage and are potential outliers (Appendix Figure 6, panel [b]). Moreover, the economy-specific estimation coefficients in Appendix Figure 7 suggest coefficient estimates for Ireland, Lithuania, and Latvia deviate from other economies. We hence exclude these five countries as well as Portugal, which saw somewhat different employment dynamics than the rest of our sample, according to our descriptive analysis (cf. Appendix Figure 1). Results are reported in column (2) of Appendix Table 3. Dropping these countries does not qualitatively affect our main result. ${ }^{30}$

Similarly, we also compute industry-specific coefficients for the relationship between robot adoption and the share of routine jobs. Appendix Figure 8 suggests that the electricity, gas, and water supply sector could be an outlier that potentially drives the overall result, together with the education and R\&D sector, which saw different routine employment trends according to our descriptive analysis. We thus reestimate our baseline regressions and sequentially omit these sectors. Columns (3) and (4) of Appendix Table 3 suggest our results are not driven by these sectors, although omitting the education and R\&D sectors in 2SLS estimation pushes statistical significance of the robot adoption parameter slightly beyond the critical $10 \%$ level (for the null hypothesis of no relationship). To check whether countries that account for the majority of robots installed are driving our estimates, we also excluded Japan, the Republic of Korea, Germany, the PRC, and the US from our estimates, leaving the baseline estimate for robotization unaffected. For the same rationale, we also excluded the high robotadopting automotive and electronic industries (columns [5] and [6] of Appendix Table 3, respectively). All parameter estimates for robot adoption where negative and statistically different from zero and t-tests do not allow rejecting the null hypothesis of equality of these parameter estimates with the baseline result (at the $10 \%$ level of statistical significance).

29 Moreover, the change in the parameter estimate appears to originate from a sample composition effect and not from omitted ICT variables: reestimating the baseline model with the 277 observations for which ICT data is available produces the same coefficient for robot adoption as in the presence of ICT variables: $-0.033^{* * *}$.

30 We also excluded several of those countries/country groups separately, with equally robust results. This also applies to excluding Japan from the analysis, which was dropped from the sample by Graetz and Michaels (2018). 
We also investigated whether a sample split at the median (0.5) of the percentile change in robot adoption affects our results. The results indicate that the parameter estimate for the slower adopters $(<0.5)$ are considerably higher but estimated with low precision, so that they are not statistically different from zero. Neither of the estimated OLS or IV parameters for the sample split are statistically speaking different from those in the baseline result of column (2) in table 3 , in line with an approximately linear relationship suggested by panel (a) in Figure $1 .{ }^{31}$

\section{Robot Adoption and Production Workers}

In Table 1, production workers are categorized as having a high content of routine manual tasks. Yet, production workers are typically labeled blue-collar workers. Hence, the relation between robots and a declining employment share of routine manual jobs could reflect a substitution of robots for blue collar production workers, instead of a substitution for routine tasks.

It is hard to rule out such an alternative interpretation. Yet, for 24 economies in our sample we are able to distinguish seven two-digit ISCO occupations that together comprise the occupational grouping labeled 'production workers' (cf. Table 1). ${ }^{32}$ The routine task intensity for each of these two-digit occupations is provided by Autor, Levy, and Murnane (2003) and, using an alternative approach, by Marcolin, Miroudot, and Squicciarini (2019). We use these to create a weighted average of the change in the employment share of production workers. The weights we use are the routine intensity index (RII) from Marcolin, Miroudot, and Squicciarini (2019) and the routine task intensity (RTI) gauged by Autor, Levy, and Murnane (2003). The task intensity by occupation is reported in Appendix Table 4. Clearly, the seven occupations labeled production workers are heterogeneous in the content of routine tasks.

The first column of Table 5 regresses the change in the employment share of production workers on robot adoption. Results indicate a significant negative relation between robot adoption and changes in the share of (routine manual task-intensive) production jobs. Subsequent columns examine the same relation, but here changes in the share of production jobs are calculated as a routine task-intensity weighted average change. Occupations that have a higher content of routine tasks receive a greater weight in this approach. ${ }^{33}$

Weighting by routine intensity strengthens the negative association between robotization and changes in the share of production jobs: the resulting parameter estimates in columns (2)-(5) are larger compared to column (1). This result is observed if we use as weights the global average RII reported by Marcolin, Miroudot, and Squicciarini (2019), see column (2), or the RII for the US or Germany (columns [3] and [4], respectively). It is also observed if we weight occupations using the RTI from Autor, Levy, and Murnane (2003), see column (5), although the parameter is estimated with less statistical precision in the OLS and 2SLS regressions. Overall, these results provide additional evidence that robot adoption is related to a decline in the share of occupations that have a higher content of routine tasks.

${ }^{31}$ We also examined results when clustering standard errors at the country level and not clustering at all. The alternative treatment of standard errors does not affect the statistical significance of the relation between robot adoption and the share of routine jobs in the OLS regressions and the coefficient $(\beta)$ is different from zero at the $1 \%$ level of statistical significance in the 2 SLS regressions.

32 The seven ISCO two-digit occupations that can be distinguished are ISCO 88 codes 71, 72, 73, 74, 81, 82, and 93. The countries for which we are able to make this split are Austria, Belgium, Czech Republic, Denmark, Estonia, Finland, France, Germany, Greece, Hungary, Ireland, Italy, Lithuania, Latvia, Malta, the Netherlands, Poland, Portugal, Romania, Slovakia, Slovenia, Spain, Sweden, Turkey, and the United Kingdom.

33 The task-intensity measures are Pearson-transformed, that is, centered at 0 with a standard deviation of 1 . We added +1 to the measure. Hence, an occupation with mean routine intensity gets a weight of 1 , a below-average routine intensity occupation a lower weight, and an above-average routine intensity occupation a weight above 1 (see Appendix Table 4). 
Table 5: Robot Adoption and Changes in the Employment Share of Production Workers

\begin{tabular}{|c|c|c|c|c|c|}
\hline & (1) & (2) & (3) & (4) & (5) \\
\hline & No Weight & $\begin{array}{c}\text { RII Weight } \\
\text { (Global Average) }\end{array}$ & RII Weight (US) & $\begin{array}{l}\text { RII Weight } \\
\text { (Germany) }\end{array}$ & RTI Weight \\
\hline \multicolumn{6}{|l|}{ (a) OLS } \\
\hline \multirow{2}{*}{$\begin{array}{l}\text { Percentile of changes } \\
\text { in robot adoption }\end{array}$} & $-0.031^{*}$ & $-0.066^{* * *}$ & $-0.065^{* * *}$ & $-0.058^{* * *}$ & -0.103 \\
\hline & $(0.02)$ & $(0.02)$ & $(0.02)$ & $(0.02)$ & $(0.08)$ \\
\hline$R^{2}$ & 0.016 & 0.036 & 0.054 & 0.035 & 0.019 \\
\hline Observations & 450 & 450 & 450 & 450 & 450 \\
\hline \multicolumn{6}{|c|}{ (b) 2SLS (IV: Replaceable tasks) } \\
\hline \multirow{2}{*}{$\begin{array}{l}\text { Percentile of changes } \\
\text { in robot adoption }\end{array}$} & $-0.083^{*}$ & $-0.122^{* *}$ & $-0.143^{* * *}$ & $-0.113^{* *}$ & $-0.318^{*}$ \\
\hline & $(0.04)$ & $(0.06)$ & $(0.05)$ & $(0.06)$ & $(0.19)$ \\
\hline $\mathrm{R}^{2}$ & -0.018 & 0.013 & -0.021 & 0.006 & -0.033 \\
\hline Observations & 450 & 450 & 450 & 450 & 450 \\
\hline
\end{tabular}

$2 S L S=$ two-stage least squares, IV = instrumental variable, $\mathrm{OLS}=$ ordinary least squares, $\mathrm{RII}=$ routine intensity index, $\mathrm{RTI}=$ routine task intensity, US = United States.

Notes: Robust standard errors in parentheses. Multi-way clustering by country and industry. Dependent variable is the change in the employment share of production workers between 2005 and 2015, with weights indicated in the column header. In panel (b), the share of replaceable tasks in an industry is used as an instrument for robot adoption. Country fixed effects are included in all regressions and partialled out in the reported $R^{2}$. ${ }^{* *} p<0.01,{ }^{* *} p<0.05,{ }^{*} p<0.1$.

Source: Author's calculations.

\section{Controlling for Long-term Industry Trends}

A remaining concern is that there could be a long-run decline in the share of routine tasks done by workers, which is more pronounced in industries investing more in robots yet not driven by robotization per se. A common way to examine this concern is to regress employment outcomes from a pre-period on the period during which robots were adopted.

Ideally, we thus relate pre-period employment outcomes on the current rise of robots. However, we are constrained by cross-country occupations data which are available from 2000 onward. By 2000, robots were already being installed (Graetz and Michaels 2018). Still, descriptive statistics in Table 2 for the number of robots per thousand persons employed in 2005 and 2015 suggest they became ubiquitous from the mid-2000s onward.

In column (1) of Table 6 we therefore regress the change in the routine employment share between 2000 and 2005 on our post-2005 measure of robot adoption. We indeed find a relationship, although the coefficient is smaller and less precisely estimated compared to our baseline results (cf. column [2] of Table 3). ${ }^{34}$ Pre-trend correlation is a necessary condition for unobserved sector heterogeneity, but it is not a sufficient condition to render identification invalid. This is partly because

34 Note that the pre-trends in employment share changes cover a 5-year period. Estimated coefficients and standard errors thus have to be approximately multiplied by a factor 2 to make them comparable with our main results for the 10-year period from 2005 to 2015. When the pre-trends are included as lagged dependent variables (columns 2 and 3 of Table 6), they accordingly have to be divided by 2 . 
Table 6: Accounting for Long-Term Industry Trends

\begin{tabular}{|c|c|c|c|c|c|}
\hline & $\begin{array}{c}(1) \\
\Delta \text { Routine } \\
\text { Employment } \\
\text { Share } \\
2000-2005\end{array}$ & $\begin{array}{l}\Delta \text { Routine } \\
\text { Employment } \\
\quad \text { Share }\end{array}$ & $\begin{array}{c}\text { (3) } \\
\Delta \text { Routine } \\
\text { Manual } \\
\text { Employment } \\
\text { Share }\end{array}$ & $\begin{array}{c}\text { (4) } \\
\Delta \text { Routine } \\
\text { Employment } \\
\text { Share }\end{array}$ & $\begin{array}{c}(5) \\
\Delta \text { Routine } \\
\text { Manual } \\
\text { Employment } \\
\text { Share }\end{array}$ \\
\hline \multicolumn{6}{|l|}{ (a) OLS } \\
\hline $\begin{array}{l}\text { Percentile of changes in } \\
\text { robot adoption }\end{array}$ & $\begin{array}{r}-0.020^{* *} \\
(0.01)\end{array}$ & $\begin{array}{r}-0.044^{* * *} \\
(0.01)\end{array}$ & $\begin{array}{r}-0.046^{* * *} \\
(0.01)\end{array}$ & $\begin{array}{r}-0.016^{* * *} \\
(0.00)\end{array}$ & $\begin{array}{r}-0.026^{* * *} \\
(0.01)\end{array}$ \\
\hline $\begin{array}{l}\text { Change in dependent } \\
\text { variable, } 2000-2005\end{array}$ & & $\begin{array}{l}0.174^{*} \\
(0.10)\end{array}$ & $\begin{array}{l}0.147^{*} \\
(0.08)\end{array}$ & & \\
\hline Industry fixed effects & No & No & No & Yes & Yes \\
\hline $\mathrm{R}^{2}$ & 0.014 & 0.035 & 0.030 & 0.007 & 0.007 \\
\hline Observations & 700 & 700 & 700 & 700 & 700 \\
\hline \multicolumn{6}{|c|}{ (b) 2SLS (IV: Replaceable tasks) } \\
\hline $\begin{array}{l}\text { Percentile of changes in } \\
\text { robot adoption }\end{array}$ & $\begin{array}{r}-0.053^{* *} \\
(0.02)\end{array}$ & $\begin{array}{r}-0.113^{* *} \\
(0.05)\end{array}$ & $\begin{array}{r}-0.114^{* *} \\
(0.05)\end{array}$ & & \\
\hline $\begin{array}{l}\text { Change in dependent } \\
\text { variable, } 2000-2005\end{array}$ & & $\begin{array}{r}0.133 \\
(0.09) \\
\end{array}$ & $\begin{array}{r}0.109 \\
(0.08) \\
\end{array}$ & & \\
\hline Industry fixed effects & No & No & No & & \\
\hline$R^{2}$ & -0.018 & -0.012 & -0.010 & & \\
\hline Observations & 700 & 700 & 700 & & \\
\hline
\end{tabular}

2SLS = two-stage least squares, IV = instrumental variable, OLS = ordinary least squares.

Notes: Robust standard errors in parentheses. Multi-way clustering by country and industry. The dependent variable is the change in the respective employment share over the respective period. The share of replaceable tasks in an industry is used as an instrument for robot adoption. Regressions include the change in the investment-to-value-added ratio and the change in (the log of) value added between 2005 and 2015 as control variables. Country fixed effects are included in all regressions and partialled out in the reported $R^{2} .{ }^{* *} p<0.01,{ }^{* *} p<0.05,{ }^{*}$ $\mathrm{p}<0.1$.

Source: Authors' calculations.

the pre-trend does not pre-date the rise of robots. Yet, to control for longer-term industry trends, we provide two additional estimation approaches: explicitly accounting for pre-trends by including the change in the routine employment share between 2000 and 2005 as a lagged dependent variable and including industry fixed effects.

Columns (2) and (3) of Table 6 add pre-trends to the regressions on changes in the routine employment share and the routine manual employment share, respectively (cf. column [2] of Table 3 and column [1] of Table 4). We observe a positive autocorrelation in employment dynamics. Yet, robot adoption adds additional information beyond those pre-trends as the coefficient remains statistically significant. The estimated coefficient is comparable to the baseline results. Perhaps the most convincing evidence that the negative relationship between routine employment shares and robot adoption is not exclusively driven by spurious industry dynamics can be found in columns (4) and (5) of Table 6, where we add industry fixed effects to our OLS regressions. ${ }^{35}$ This is a restrictive model that

35 We cannot estimate the model with industry fixed effects using 2SLS because the instrument only varies across industries. 
assumes industry-specific time trends in levels and thus not only accounts for heterogeneous industry employment trends but also removes a considerable degree of variation in the data that may be relevant for identification. Yet, the negative association between robotization and routine employment trends is still observed and statistically significant.

\section{Global Developments in Robot Adoption}

As discussed in section II, advances in the technical ability of robots might relate to the "reshoring" of jobs to advanced countries. For example, Faber (2018) observes a decrease in labor demand in Mexico associated with robot adoption in the US. We explore this relation in a cross-country context using two measures of robot adoption that vary across industries but not across countries. First, we take global averages, defined as the cross-country mean of the percentile change in robot adoption by industry. This reflects the idea that in an interconnected world, those industries with higher robot adoption will see faster declines in routine employment shares regardless of the location of production. Second, we use robot adoption of US industries to represent global industry trends.

Results are reported in Table 7. In columns (1) and (2) the global averages of industry-specific robot adoption are used. The regressions suggest a statistically significant and negative relation between changes in the routine employment share and global trends in robot adoption. ${ }^{36}$ Interestingly, the positive interaction between robot adoption and EMTEs shown in column (2) no longer makes up for the negative overall robot adoption parameter: the hypothesis that the sum of both parameters adds up to zero can be rejected at the $5 \%$ level of statistical significance. This suggests that global developments in robot adoption impact labor markets in EMTEs. Note, however, this is not observed if we use robot adoption in US industries to characterize global trends (see column [4]). ${ }^{37}$ Nevertheless, these exploratory regressions provide suggestive evidence for the potential relevance of global production networks and associated job reshoring patterns due to automation, which remains an interesting area for further research.

Table 7: Global Industry Trends in Robot Adoption

\begin{tabular}{lcccc}
\hline & $(1)$ & $(2)$ & $(3)$ & $(4)$ \\
Robot Measure & Global Average & Global Average & US & US \\
\hline & $\begin{array}{c}\Delta \text { Routine } \\
\text { Employment } \\
\text { Share }\end{array}$ & $\begin{array}{c}\Delta \text { Routine } \\
\text { Employment } \\
\text { Share }\end{array}$ & $\begin{array}{c}\Delta \text { Routine } \\
\text { Employment } \\
\text { Share }\end{array}$ & $\begin{array}{c}\Delta \text { Routine } \\
\text { Employment } \\
\text { Share }\end{array}$ \\
\hline (a) OLS & \multicolumn{5}{c}{} \\
\hline Alternative measure robot adoption & $-0.084^{* * *}$ & $-0.101^{* * *}$ & $-0.045^{* * *}$ & $-0.052^{* * *}$ \\
& $(0.03)$ & $(0.04)$ & $(0.01)$ & $(0.02)$ \\
$\begin{array}{l}\text { Alternative measure robot adoption } \\
\text { x dummy EMTE }\end{array}$ & & $0.054^{* * *}$ & & $0.052^{* * *}$ \\
& & $(0.02)$ & & $(0.02)$ \\
\hline
\end{tabular}

continued on next page

36 Using measures of robot adoption that vary across industries but not across countries, we also do not find a statistical significant association between robot adoption and the average annual percentage growth in employment in specifications with and without the interaction with a dummy for EMTEs.

37 It is also not observed if we use robot adoption in German industries to characterize global trends. 
Table 7 continued

\begin{tabular}{|c|c|c|c|c|}
\hline & (1) & (2) & (3) & (4) \\
\hline \multirow[t]{2}{*}{ Robot Measure } & Global Average & Global Average & US & US \\
\hline & $\begin{array}{c}\Delta \text { Routine } \\
\text { Employment } \\
\text { Share }\end{array}$ & $\begin{array}{c}\Delta \text { Routine } \\
\text { Employment } \\
\text { Share }\end{array}$ & $\begin{array}{c}\Delta \text { Routine } \\
\text { Employment } \\
\text { Share }\end{array}$ & $\begin{array}{c}\Delta \text { Routine } \\
\text { Employment } \\
\text { Share }\end{array}$ \\
\hline $\mathrm{R}^{2}$ & 0.034 & 0.039 & 0.039 & 0.043 \\
\hline Observations & 700 & 700 & 700 & 700 \\
\hline \multicolumn{5}{|l|}{ (b) 2SLS (IV: Replaceable tasks) } \\
\hline Alternative measure robot adoption & $\begin{array}{r}-0.128^{* * *} \\
(0.05)\end{array}$ & $\begin{array}{r}-0.152^{* * *} \\
(0.06)\end{array}$ & $\begin{array}{r}-0.067^{* * *} \\
(0.02)\end{array}$ & $\begin{array}{r}-0.080^{* * *} \\
(0.03)\end{array}$ \\
\hline $\begin{array}{l}\text { Alternative measure robot adoption } \\
\text { x dummy EMTE }\end{array}$ & & $\begin{array}{l}0.089^{* *} \\
(0.04)\end{array}$ & & $\begin{array}{l}0.086^{* *} \\
(0.03)\end{array}$ \\
\hline$R^{2}$ & 0.026 & 0.030 & 0.030 & 0.033 \\
\hline Observations & 700 & 700 & 700 & 700 \\
\hline
\end{tabular}

$2 \mathrm{SLS}=$ two-stage least squares, $\mathrm{EMTE}=$ emerging market and transition economy, $\mathrm{IV}=$ instrumental variable, OLS = ordinary least squares, US = United States.

Notes: Robust standard errors in parentheses. Multi-way clustering by country and industry. The dependent variable is the change in the routine employment share between 2005 and 2015. Column headers indicate which type of global measure has been used to calculate industry-specific robot adoption. The share of replaceable tasks in an industry is used as an instrument for robot adoption. Regressions include the change in the investment-to-value-added ratio and the change in (the log of) value added between 2005 and 2015 as control variables. Country fixed effects are included in all regressions and partialled out in the reported R2. ${ }^{* *} p<0.01,{ }^{* *} p<0.05,{ }^{*} p<0.1$.

Source: Authors' calculations.

\section{CONCLUDING REMARKS}

We study the relation between industrial robots and occupational shifts by task content. Using a panel of 19 industries in 37 high-income and EMTEs from 2005 to 2015, we find that increased use of robots is associated with positive changes in the employment share of nonroutine analytic jobs and negative changes in the share of routine manual jobs. The patterns that we document are robust to instrumental variable estimation and the inclusion of various control variables, but they differ across levels of economic development: we observe a significant relation for high-income economies, but not in EMTEs. Finally, we do not find a significant relation between industrial robot adoption and aggregate employment growth. This suggests that industrial robots did not replace jobs, but they did impact task demand and thus had disruptive effects on employment.

Our analysis covered industrial robots, but much of the recent robotic developments have been taking place in services, such as the emergence of medical robots, logistics handling robots, and delivery by means of drones. It is therefore likely that robots will continue to disrupt labor markets and result in reallocation dynamics. Studying and understanding the socioeconomic consequences of these disruptions will be important (see, for example, Dauth et al. 2019). Retraining and reskilling of workers seems inevitable, which should spur a major rethinking about educational goals, lifelong learning, and developing the right skills (Kim and Park 2020). 


\section{APPENDIX}

Figure A1.1: Changes in Employment Shares by Economy and Task Type between 2005 and 2015

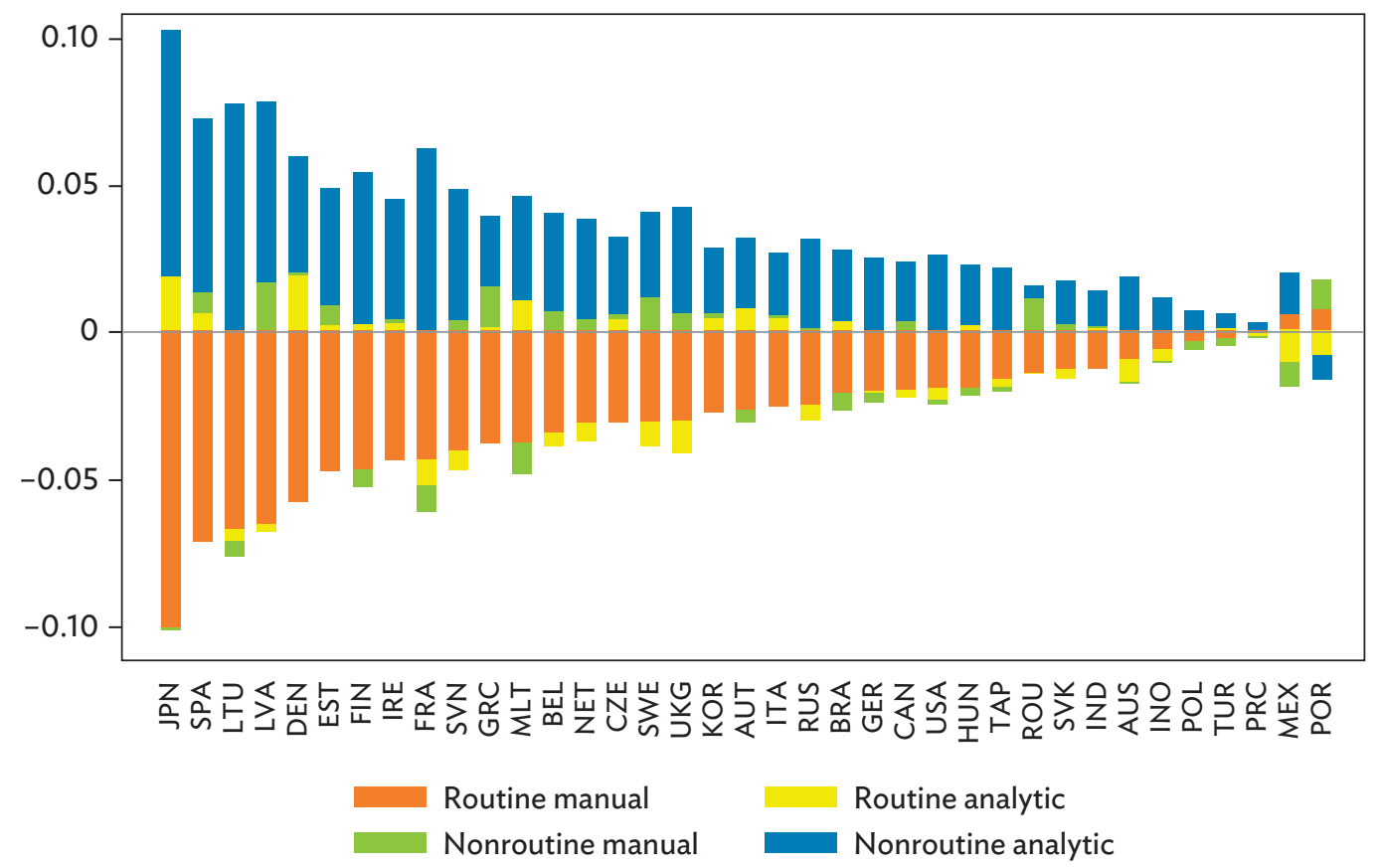

AUS = Australia; $\mathrm{AUT}=$ Austria; $\mathrm{BEL}=$ Belgium; $\mathrm{BRA}=$ Brazil; $\mathrm{CAN}=$ Canada; $\mathrm{CZE}=$ Czech Republic; $\mathrm{DEN}=$ Denmark; $\mathrm{EST}=$ Estonia; FIN = Finland; FRA = France; GER = Germany; GRC = Greece; HUN = Hungary; IND = India; INO = Indonesia; IRE = Ireland; ITA = Italy; JPN = Japan; KOR = Republic of Korea; LTU = Lithuania; LVA = Latvia; MEX = Mexico; MLT = Malta; NET = Netherlands; $\mathrm{POL}=$ Poland POR = Portugal; $\mathrm{PRC}=$ People's Republic of China; $\mathrm{ROU}=$ Romania; RUS = Russian Federation; SPA = Spain; SVN = Slovenia; $S V K=$ Slovakia; $S W E=$ Sweden; TAP = Taipei,China; $T U R=$ Turkey; UKG = United Kingdom; USA = United States. Notes: Change in employment shares between 2005 and 2015. For aggregation, industries included in the sample are weighted using their 2005 employment share within the sample for each economy. Agriculture is omitted in the calculation for Ireland, which reports a sudden swing in the routine manual employment share (see subsection V.B.1 for robustness check excluding Ireland). Source: Updated occupations database from Reijnders and de Vries (2018) by Buckley et al. (2020). 
Figure A1.2: Changes in Employment Shares by Industry and Task Type between 2005 and 2015

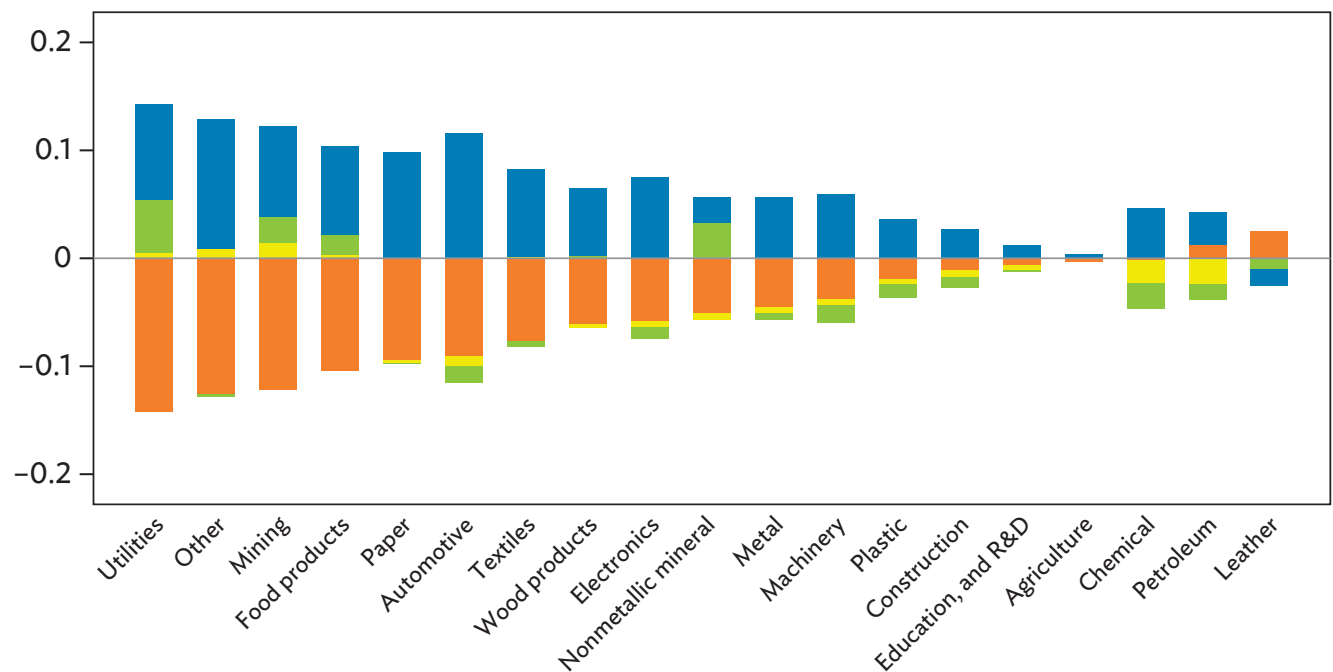

Routine manual

Nonroutine manual

Routine analytic

Nonroutine analytic

$R \& D=$ research and development.

Note: Change in employment shares by industry between 2005 and 2015. Unweighted average changes.

Source: Updated occupations database from Reijnders and de Vries (2018) by Buckley et al. (2020).

Figure A1.3: Robotization by Economy in 2005 and 2015

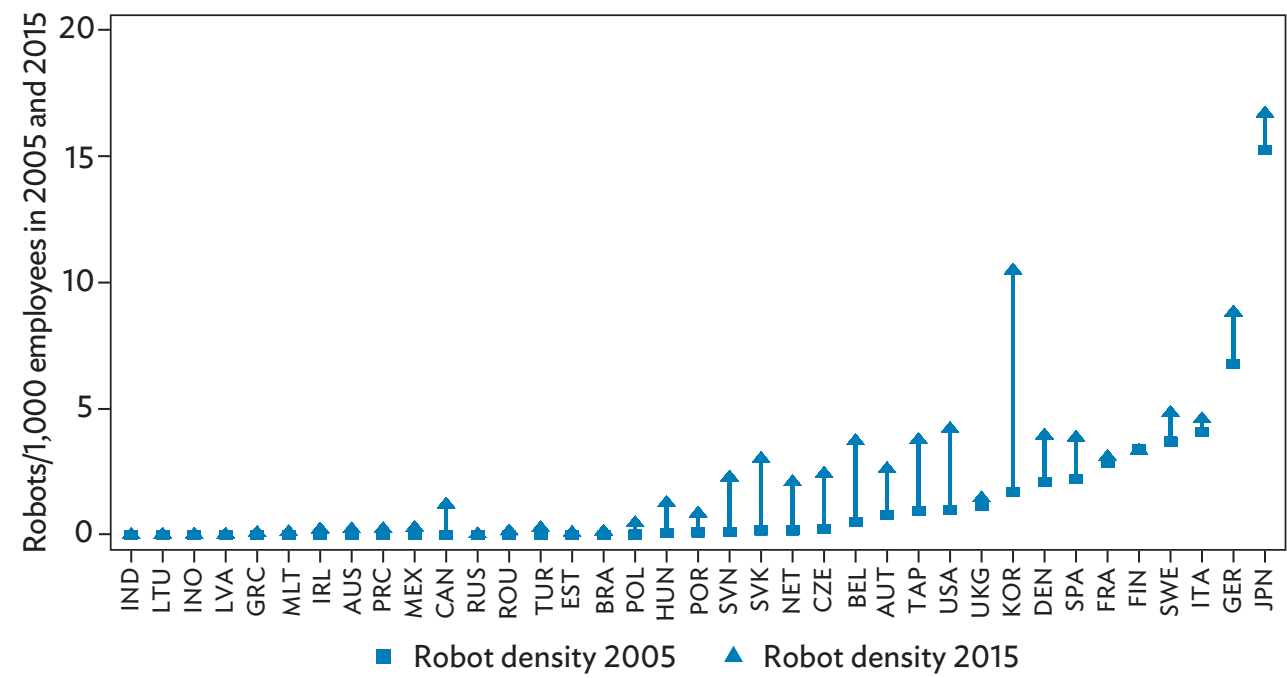

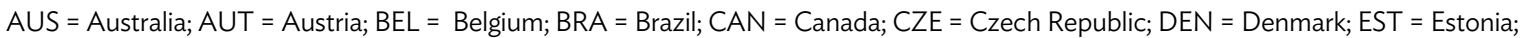
$\mathrm{FIN}=$ Finland; FRA = France; GER = Germany; GRC = Greece; HUN = Hungary; IND = India; INO = Indonesia; IRE = Ireland; ITA = Italy; JPN = Japan; KOR = Republic of Korea; $L T U$ = Lithuania; LVA = Latvia; MEX = Mexico; MLT = Malta; NET = Netherlands; $\mathrm{POL}=$ Poland; $\mathrm{POR}=$ Portugal; $\mathrm{PRC}=$ People's Republic of China; $\mathrm{ROU}=$ Romania; RUS = Russian Federation; $\mathrm{SPA}=\mathrm{Spain} ; \mathrm{SVN}=$ Slovenia; $S V K=$ Slovakia; SWE = Sweden; TAP = Taipei,China; TUR = Turkey; UKG = United Kingdom; USA = United States.

Note: Robot stock per thousand employees by economy in 2005 (squares) and 2015 (triangles).

Sources: Robot stock from the International Federation of Robotics and employment from Reijnders and de Vries (2018) updated by Buckley et al. (2020); Authors' calculations. 
Figure A1.4: Robotization by Industry in 2005 and 2015

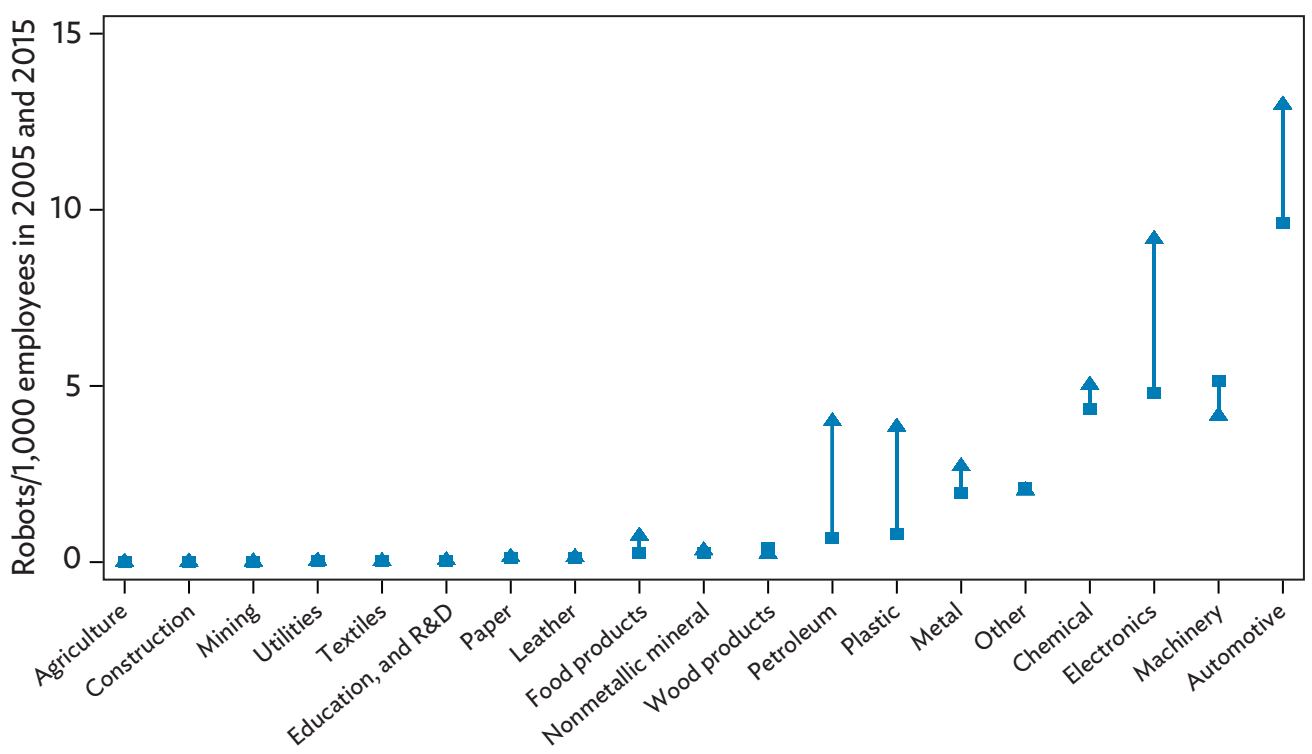

- Robot density 2005 • Robot density 2015

$R \& D=$ research and development.

Note: Robot stock per thousand persons employed by industry in 2005 (squares) and 2015 (triangles).

Sources: Robot stock from International Federation of Robotics and employment from Reijnders and de Vries (2018) updated by Buckley et al. (2020); Authors' calculations.

Figure A1.5: Robotization by Industry in the People's Republic of China and Germany, 2015

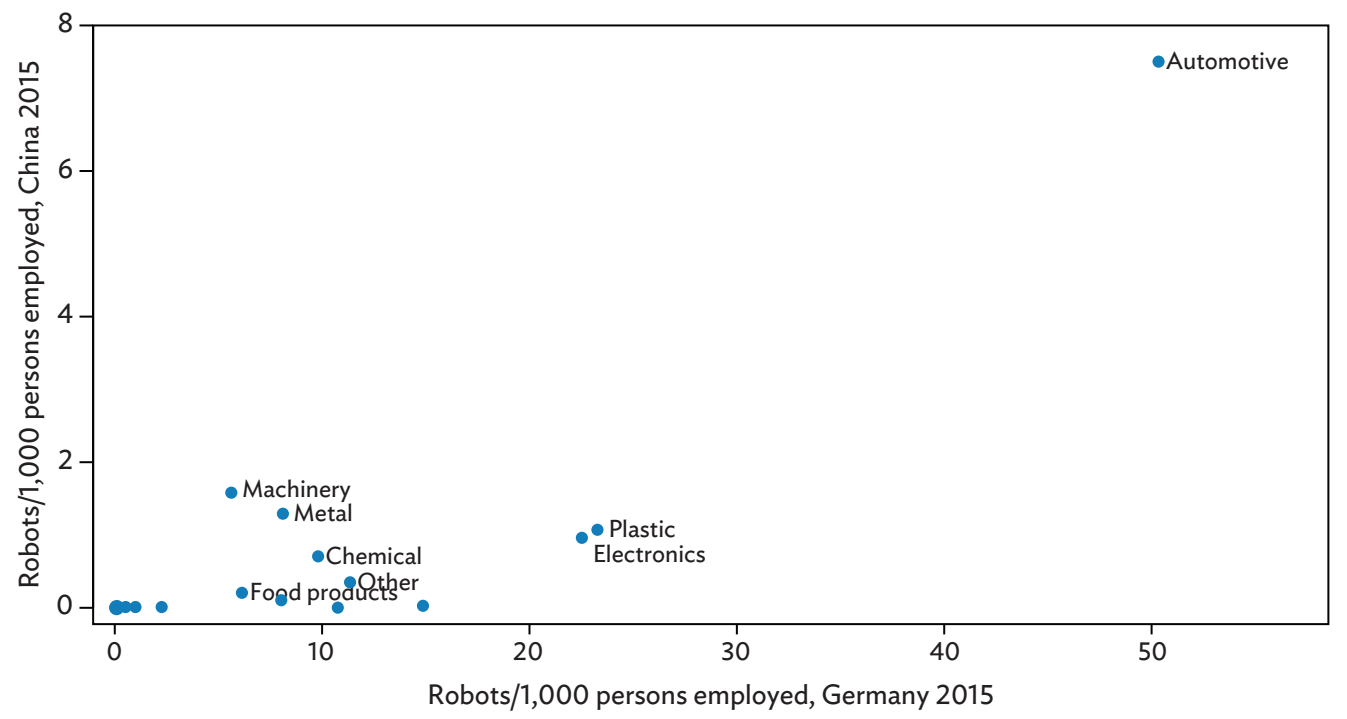

Note: Robot stock per thousand persons employed by industry.

Sources: Robot stock from International Federation of Robotics and employment from Reijnders and de Vries (2018) updated by Buckley et al. (2020); Authors' calculations. 
Figure A1.6: Residual Patterns for Main Ordinary Least Squares Specification

(a) Residuals vs fitted values

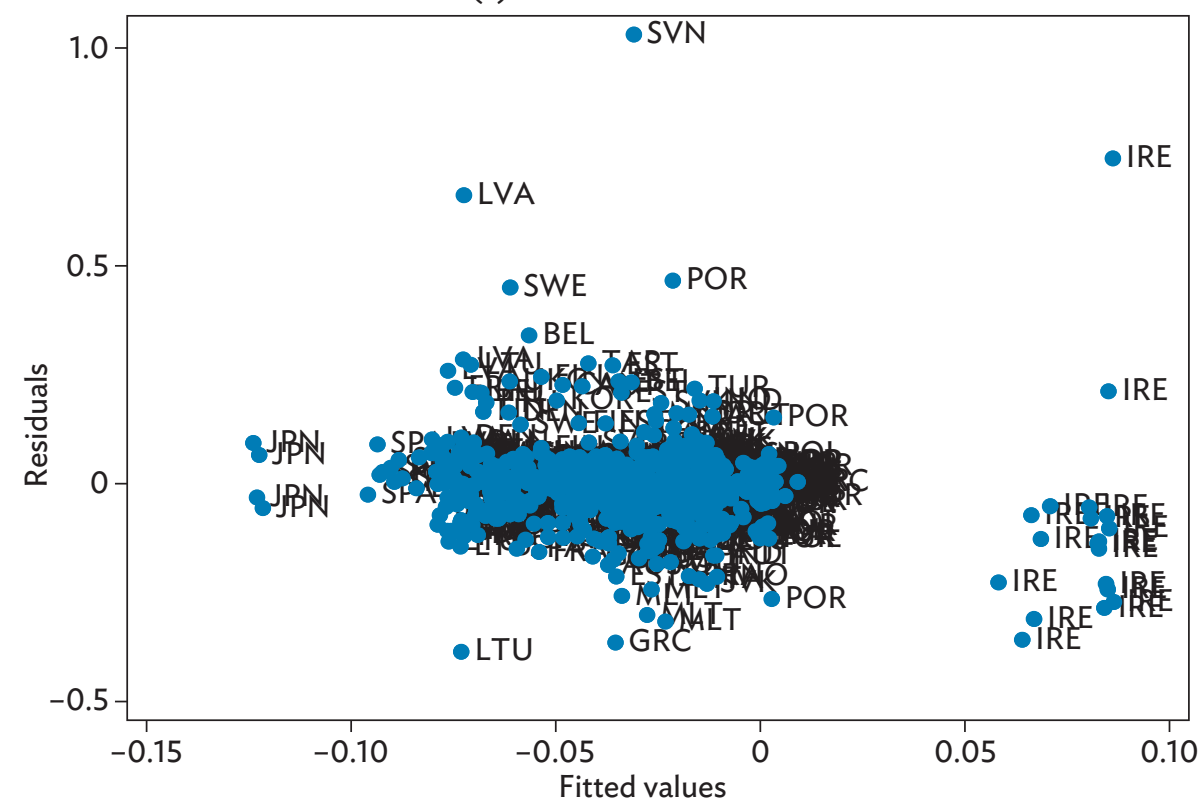

(b) Leverage vs residuals

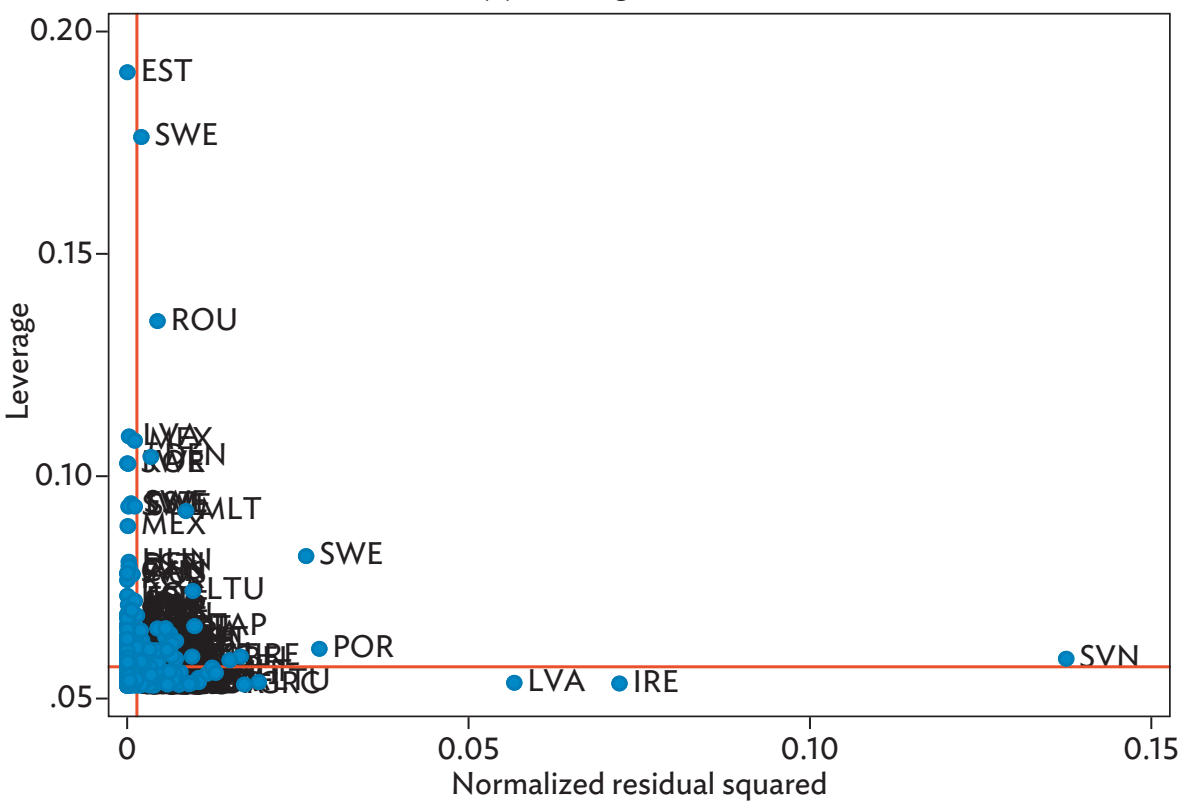

AUS = Australia; $\mathrm{AUT}=$ Austria; $\mathrm{BEL}=$ Belgium; $\mathrm{BRA}=$ Brazil; $\mathrm{CAN}=$ Canada; $\mathrm{CZE}=$ Czech Republic; DEN $=$ Denmark; EST $=$ Estonia; FIN = Finland; FRA = France; GER = Germany; GRC = Greece; HUN = Hungary; IND = India; INO = Indonesia; IRE = Ireland; ITA = Italy; JPN = Japan; KOR = Republic of Korea; LTU = Lithuania; LVA = Latvia; MEX = Mexico; MLT = Malta; NET = Netherlands; $\mathrm{OLS}=$ ordinary least squares; $\mathrm{POL}=$ Poland $\mathrm{POR}=$ Portugal $; \mathrm{PRC}=$ People's Republic of China; $\mathrm{ROU}=$ Romania; $\mathrm{RUS}=$ Russian Federation; SPA = Spain; SVN = Slovenia; SVK = Slovakia; SWE = Sweden; TAP = Taipei,China; TUR = Turkey; UKG = United Kingdom; USA = United States.

Notes: Panel (a) plots the OLS residuals (deviation of predicted from actual value, vertical axis) against the fitted values from the OLS model (horizontal axis). Panel (b) plots the leverage (influence) every observation gets in the OLS regression, a measure of distance from the mean in the explanatory variables (vertical axis), against normalized squared residuals (horizontal axis). All values are based on column (2) in panel (a) of Table 3.

Source: Authors' calculations. 


\section{Figure A1.7: Economy-Specific Ordinary Least Squares Coefficients}

(a) Overall distribution

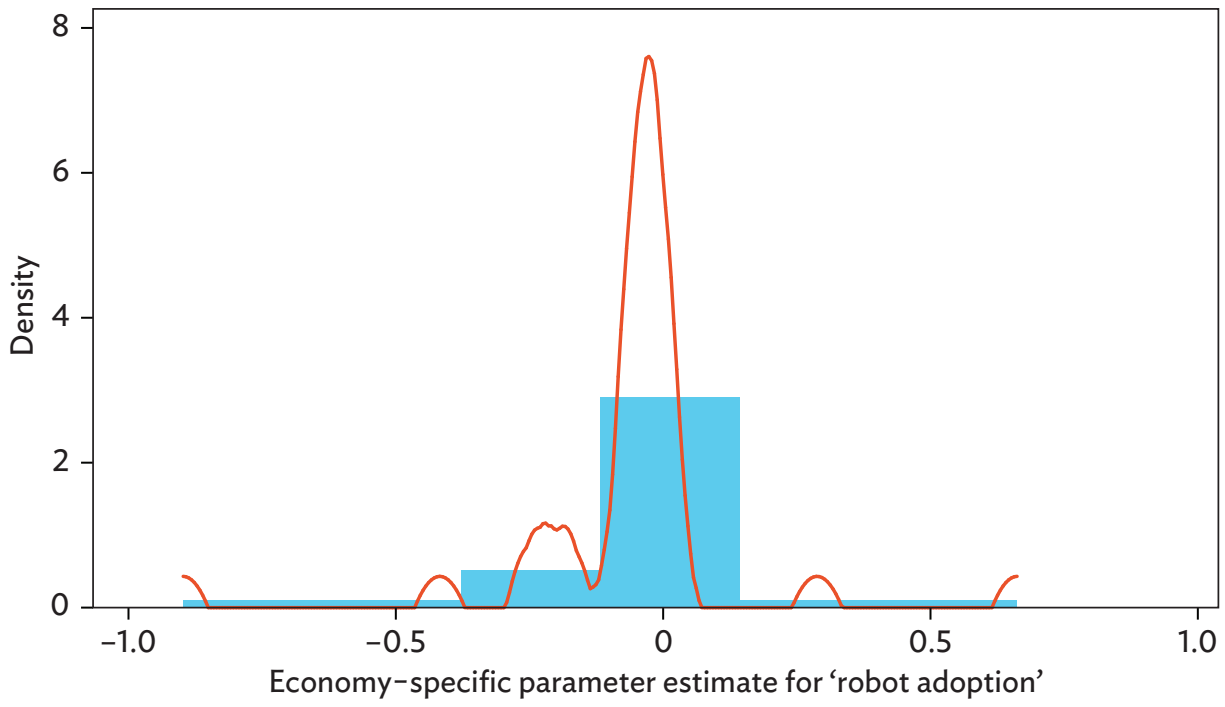

Histogram Kernel density estimate

(b) Economy-specific coefficient plot

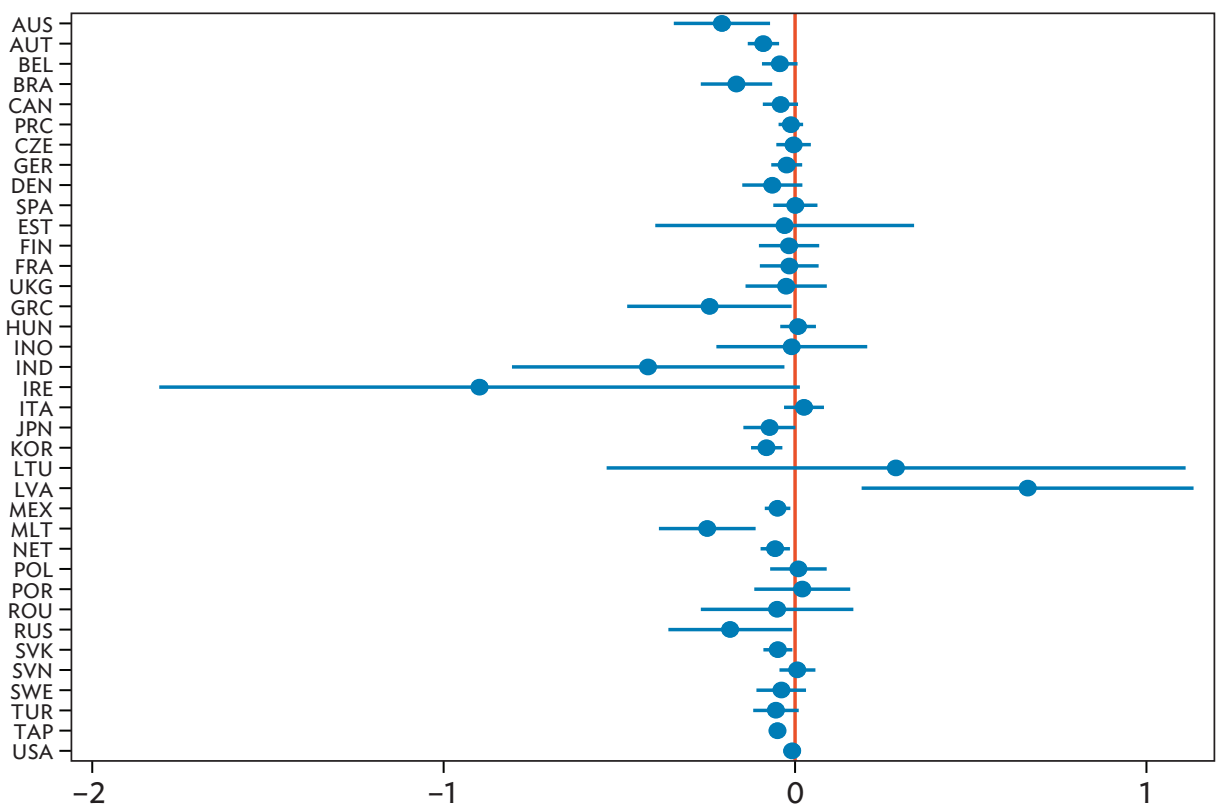

AUS = Australia; $\mathrm{AUT}=$ Austria; $\mathrm{BEL}=$ Belgium; $\mathrm{BRA}=$ Brazil; $\mathrm{CAN}=$ Canada; $\mathrm{CZE}=$ Czech Republic; $\mathrm{DEN}=$ Denmark; $\mathrm{EST}=$ Estonia; FIN = Finland; FRA = France; GER = Germany; GRC = Greece; HUN = Hungary; IND = India; INO = Indonesia; IRE = Ireland; ITA =Italy; $J P N=$ Japan; KOR = Republic of Korea; LTU = Lithuania; LVA = Latvia; MEX = Mexico; MLT = Malta; NET = Netherlands; $\mathrm{OLS}=$ ordinary least squares; $\mathrm{POL}=$ Poland; $\mathrm{POR}=$ Portugal; $\mathrm{PRC}=$ People's Republic of China; $\mathrm{ROU}=$ Romania; RUS = Russian Federation; SPA = Spain; SVN = Slovenia; SVK = Slovakia; SWE = Sweden; TAP = Taipei,China; TUR = Turkey; UKG = United Kingdom; USA = United States.

Notes: Figure 7 displays economy-specific coefficients for an OLS regression model where we augment the specification in column (2) of Table 3 (panel [a]) with an interaction of robot adoption with economy dummy variables. The distribution of those economy-specific interactions with robot adoption is depicted in Figure 7 (a) using a histogram and a kernel density estimator. Figure 7 (b) displays the estimated coefficients by economy, including their $95 \%$ confidence interval.

Source: Authors' calculations. 
Figure A1.8: Industry-Specific Ordinary Least Squares Coefficients

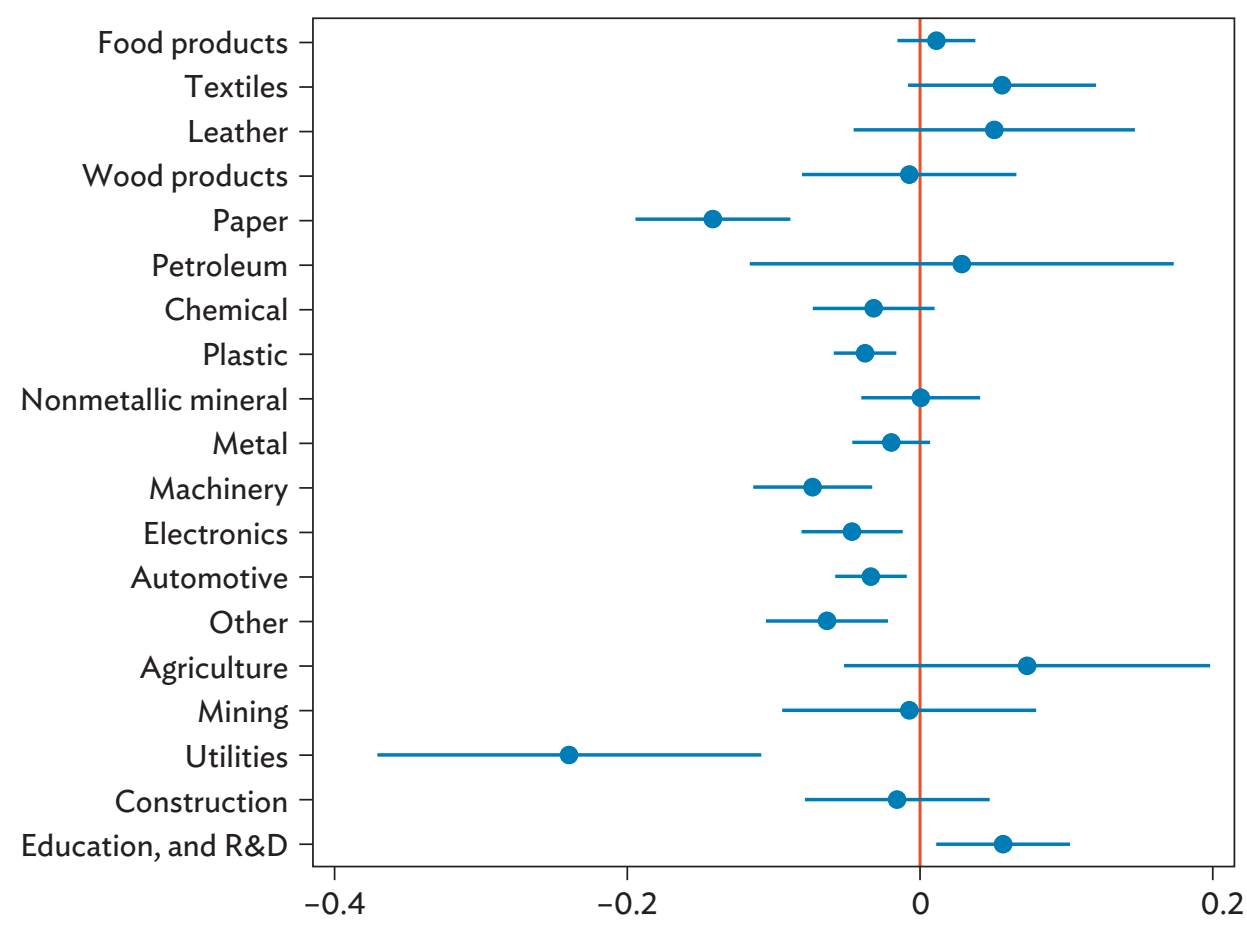

$R \& D=$ research and development.

Notes: Figure displays industry-specific coefficients for a regression model where we augment the specification in column (2) of Table 3 (panel [a]) with an interaction of robot adoption with industry dummy variables. The estimated coefficients by industry are depicted together with their $95 \%$ confidence interval.

Source: Authors' calculations. 
Table A1.1: Industry Codes

\begin{tabular}{|c|c|c|}
\hline ISIC Rev 3.1 Code & Short Description & Long Description \\
\hline AtB & Agriculture & Agriculture, hunting, forestry and fishing \\
\hline $15 \mathrm{t} 16$ & Food products & Food, beverages and tobacco \\
\hline $17 \mathrm{t} 18$ & Textiles & Textiles and textile \\
\hline 19 & Leather & Leather, leather and footwear \\
\hline 20 & Wood products & Wood and products of wood and cork \\
\hline $21 \mathrm{t} 22$ & Paper & Pulp, paper, printing and publishing \\
\hline 23 & Petroleum & Coke, refined petroleum and nuclear fuel \\
\hline 24 & Chemical & Chemicals and chemical \\
\hline 25 & Plastic & Rubber and plastics \\
\hline 26 & Nonmetallic mineral & Other nonmetallic mineral \\
\hline $27 \mathrm{t} 28$ & Metal & Basic metals and fabricated metal \\
\hline 29 & Machinery & Machinery, not elsewhere classified (nec) \\
\hline $30 \mathrm{t} 33$ & Electronics & Electrical and optical equipment \\
\hline $34 \mathrm{t} 35$ & Automotive & Transport equipment \\
\hline $36 \mathrm{t} 37$ & Other & Manufacturing nec; recycling \\
\hline C & Mining & Mining and quarrying \\
\hline E & Utilities & Electricity, gas and water supply \\
\hline $\mathrm{F}$ & Construction & Construction \\
\hline M & Education, and R\&D & Education, and R\&D \\
\hline
\end{tabular}

$I S I C=$ International Standard Industrial Classification, nec = not elsewhere classified, R\&D = research and development. Source: Authors' adaptation of ISIC Rev. 3.1 codes. 
Table A1.2: 2-Stage Least Squares Results for Reaching and Handling

\begin{tabular}{|c|c|c|c|c|}
\hline & (1) & $\begin{array}{c}\text { (2) } \\
\Delta \text { Routine } \\
\text { Employment } \\
\text { Share }\end{array}$ & $\begin{array}{c}(3) \\
\Delta \text { Routine } \\
\text { Employment } \\
\text { Share }\end{array}$ & $\begin{array}{c}\text { (4) } \\
\text { Percentile of } \\
\text { Changes in robot } \\
\text { Adoption }\end{array}$ \\
\hline Percentile of changes in robot adoption & $\begin{array}{r}-1.586 \\
(3.81)\end{array}$ & $\begin{array}{r}-0.134^{*} \\
(0.08)\end{array}$ & $\begin{array}{r}-0.169 \\
(0.11)\end{array}$ & \\
\hline $\begin{array}{l}\text { Percentile of changes in robot adoption } \\
x \text { dummy EMTE }\end{array}$ & & & $\begin{array}{l}0.149 \\
(0.10)\end{array}$ & \\
\hline Reaching and handling tasks & & & & $\begin{array}{r}1.438^{* * *} \\
(0.43)\end{array}$ \\
\hline Cragg-Donald Wald F statistic & & & & 129.47 \\
\hline Kleibergen-Paap F-statistic & & & & 11.44 \\
\hline $\begin{array}{l}\text { Kleibergen-Paap under identification } \\
\text { test ( } p \text {-value) }\end{array}$ & & & & 0.025 \\
\hline$R^{2}$ & -0.013 & -0.047 & -0.075 & \\
\hline Observations & 700 & 700 & 700 & 700 \\
\hline Number of economies & 37 & 37 & 37 & 37 \\
\hline
\end{tabular}

2SLS = two-stage least squares, $\mathrm{EMTE}=$ emerging market and transition economy.

Notes: Robust standard errors in parentheses. Multi-way clustering by country and industry. The dependent variable employment growth in column (1) is the average annual growth in employment for the period 2005-2015. The dependent variable in columns (2)-(3) is the change in the routine employment share between 2005 and 2015. Column (4) reports the first stage for 2SLS estimation. Reaching and handling tasks are used as an instrument for robot adoption. Regressions include the change in the investment-to-value-added ratio and the change in (the log of) value added between 2005 and 2015 as control variables. Country fixed effects are included in all regressions and partialled out in the reported $R^{2}$. ${ }^{* * *} p<0.01,{ }^{* *} p<0.05,{ }^{*} p<0.1$.

Source: Authors' calculations. 


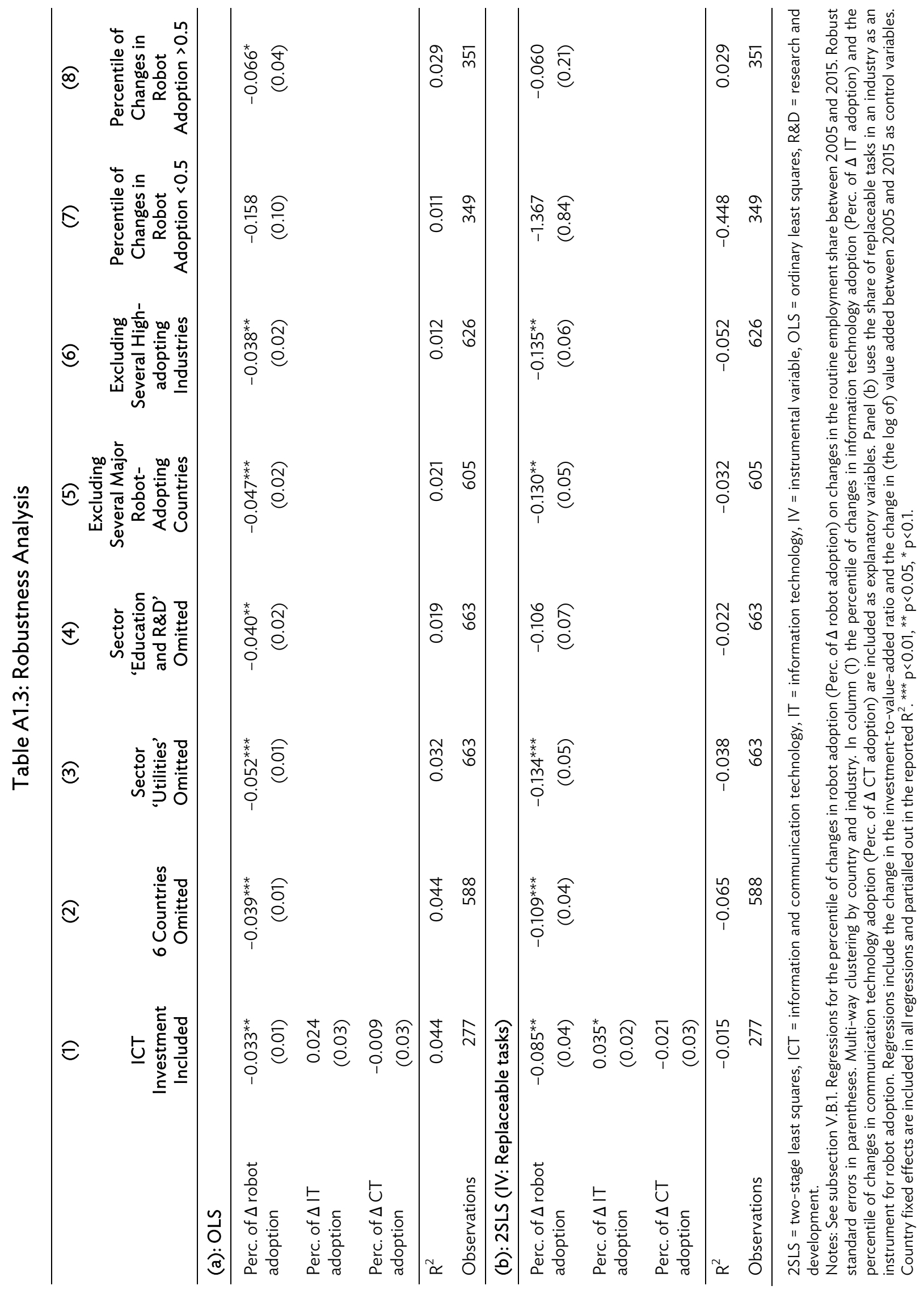


Table A1.4: Routine Task-Intensity of Occupations Grouped as 'Production Workers'

\begin{tabular}{llcccc}
\hline $\begin{array}{l}\text { ISCO 88 } \\
\text { Code }\end{array}$ & \multicolumn{1}{c}{ Description Occupation } & $\begin{array}{c}\text { RII (Global } \\
\text { Average) }\end{array}$ & RII (US) & $\begin{array}{c}\text { RII } \\
\text { (Germany) }\end{array}$ & RTI \\
\hline 71 & Extraction and building trades workers & 1.031 & 1.209 & 0.955 & 0.815 \\
72 & Metal, machinery and related trade work & 1.269 & 1.209 & 0.955 & 1.457 \\
73 & $\begin{array}{l}\text { Precision, handicraft, craft printing and } \\
\text { related trade workers }\end{array}$ & 0.952 & 1.598 & 0.477 & 2.589 \\
74 & Other craft and related trade workers & 0.810 & 0.626 & 0.477 & 2.238 \\
81 & Stationary plant and related operators & 2.930 & 2.181 & 3.342 & 1.323 \\
82 & Machine operators and assemblers & 2.480 & 3.541 & 2.865 & 1.493 \\
93 & $\begin{array}{l}\text { Laborers in mining, construction, } \\
\text { manufacturing and transport }\end{array}$ & 2.886 & 2.375 & 3.342 & 1.449 \\
\hline
\end{tabular}

ISCO = International Standard Classification of Occupations, RII = routine intensity index, RTI = routine task intensity, US = United States. Notes: The RII is from Marcolin, Miroudot, and Squicciarini (2019) and the RTI from Autor, Levy, and Murnane (2003). The measures are Pearson-transformed, that is, centered at 0 with a standard deviation of 1 . We added +1 to the measure. Hence, an occupation with mean routine intensity gets a weight of 1 , a below-average routine intensity occupation a lower weight, and an above-average routine intensity occupation a weight above 1.

Source: Authors' calculations. 


\section{REFERENCES}

Acemoglu, Daron, and David Autor. 2011. "Skills, Tasks and Technologies: Implications for Employment and Earnings." In Handbook of Labour Economics, Vol. 4, 1043-71. Elsevier.

Acemoglu, Daron, and Pascual Restrepo. 2018. "Modeling Automation." American Economic Review Papers and Proceedings 108: 48-53.

- 2019. "Automation and New Tasks: How Technology Displaces and Reinstates Labor." Journal of Economic Perspectives 33 (2): 3-30.

_. 2020. "Robots and Jobs: Evidence from US Local Labor Markets." Journal of Political Economy, forthcoming.

Autor, David. 2015. "Why are There Still so Many Jobs? The History and Future of Workplace Automation." Journal of Economic Perspectives 29 (3): 3-30.

Autor, David H., Lawrence F. Katz, and Alan B. Krueger. 1998. "Computing Inequality: Have Computers Changed the Labor Market?” The Quarterly Journal of Economics 113 (4): 1169-213.

Autor, David H., Frank Levy, and Richard J. Murnane. 2003. "The Skill Content of Recent Technological Change: An Empirical Exploration." The Quarterly Journal of Economics 118 (4): 1279-333.

Buckley, Peter J., Roger Strange, Marcel P. Timmer, and Gaaitzen J. de Vries. 2020. "Catching-up in the Global Factory: Analysis and Policy Implications." Journal of International Business Policy 3 (2): 79-106.

Cameron, A. Colin, Jonah B. Gelbach, and Douglas L. Miller. 2012. "Robust Inference with Multi-Way Clustering." Journal of Business \& Economic Statistics 29 (2): 238-49.

Cheng, Hong, Ruixue Jia, Dandan Li, and Hongbin Li. 2019. "The Rise of Robots in China." Journal of Economic Perspectives 33 (2): 71-88.

Cortes, Guido M., Nir Jaimovich, Christopher J. Nekarda, and Henry E. Siu. 2020. "The Dynamics of Disappearing Routine Jobs: A Flows Approach." Labour Economics 65: 101823.

Dauth, Wolfgang, Sebastian Findeisen, Jens Suedekum, and Nicole Woessner. 2019. "The Adjustment of Labor Markets to Robots." Mimeo University of Würzburg.

De La Rica, Sara, Lucas Gortazar, and Piotr Lewandowski. 2020. “Job Tasks and Wages in Developed Countries: Evidence from PIAAC.” Labour Economics 65: 101845.

The Economist. 2017. "Sewing Clothes still Needs Human Hands. But for How Much Longer?" August 24.

Faber, Marius. 2018. "Robots and Reshoring: Evidence from Mexican Local Labor Markets." WWZ Working Paper 2018/27. 
Feenstra, Robert C. 2008. "Offshoring in the Global Economy.” The Ohlin Lectures.

Frey, Carl, and Michael Osborne. 2017. "The Future of Employment: How Susceptible are Jobs to Computerisation?” Technological Forecasting and Social Change 114: 254-80.

Ghodsi, Mahdi, Oliver Reiter, Robert Stehrer, and Roman Stöllinger. 2020. "Robotisation, Employment and Industrial Growth Intertwined across Global Value Chains.” WIIW Working Paper No. 177.

Goos, Maarten, Alan Manning, and Anna Salomons. 2014. "Explaining Job Polarization: Routine-Biased Technological Change and Offshoring." American Economic Review 104 (8): 2509-26.

Graetz, Georg, and Guy Michaels. 2018. "Robots at Work." Review of Economics and Statistics 100 (5): 753-68.

Harrigan, James, Ariell Reshef, and Farid Toubal. 2016. "The March of the Techies: Technology, Trade, and Job Polarization in France, 1994-2007.” NBER Working Paper No. 22110.

International Federation of Robotics (IFR). 2012. "World Robotics Industrial Robots 2012." Report.

Kim, Jinyoung, and Cyn-Young Park. 2020. "Education, Skill Training, and Lifelong Learning in the Era of Technological Revolution.” ADB Economics Working Paper Series No. 606.

Krenz, Astrid, Klaus Prettner, and Holger Strulik. 2018. "Robots, Reshoring, and the Lot of Low-Skilled Workers. CEGE Working Paper No. 351.

Lin, Olivia. 2018. “Chinese Robotic Firms Thrive, Thanks to Subsidies.” Asia Times, May 8.

Marcolin, Luca, Sébastien Miroudot, and Mariagrazia Squicciarini. 2019. "To be (Routine) or Not to be (Routine), that is the Question: A Cross-Country Task-Based Answer." Industrial and Corporate Change 28 (3): 477-501.

Martens, Bertin, and Songül Tolan. 2018. "Will this Time be Different? A Review of the Literature on the Impact of Artificial Intelligence on Employment, Incomes and Growth." JRC Digital Economy Working Paper 2018-08.

Michaels, Guy, Ashwini Natraj, and John Van Reenen. 2014. "Has ICT Polarized Skill Demand? Evidence from Eleven Countries over Twenty-Five Years." Review of Economics and Statistics 96 (1): 60-77.

Reijnders, Laurie S.M., and Gaaitzen J. de Vries. 2018. "Technology, Offshoring and the Rise of Nonroutine Jobs.” Journal of Development Economics 135: 412-32.

Ross, Matthew B. 2017. "Routine-Biased Technical Change: Panel Evidence of Task Orientation and Wage Effects." Labour Economics 48: 198-214.

Stehrer, Robert, Alexandra Bykova, Kirsten Jäger, Oliver Reiter, and Monika Schwarzhappel. 2019. "Industry Level Growth and Productivity Data with Special Focus on Intangible Assets." WIIW report on methodologies and data construction for the EU KLEMS Release 2019. 
Timmer, Marcel P., Erik Dietzenbacher, Bart Los, Robert Stehrer, and Gaaitzen J. de Vries. 2015. "An Illustrated User Guide to the World Input-Output Database: The Case of Global Automotive Production." Review of International Economics 23 (3): 575-605.

Van Reenen, John. 2011. "Wage Inequality, Technology and Trade: 21st Century Evidence." Labour Economics 18 (6): 730-41.

Yang, Zi. 2017. "Who Will Satisfy China's Thirst for Industrial Robots?” The Diplomat, May 19. 


\section{The Rise of Robots and the Fall of Routine Jobs}

This paper examines the impact of industrial robots on jobs by combining data on robot adoption and occupations by industry in 37 economies for the period 2005-2015. The authors exploit differences across industries in technical feasibility, that is the industry's share of tasks replaceable by robots, to identify the impact of robot usage on employment. The data allow them to differentiate effects by the routine intensity of employment. The authors find that a rise in robot adoption relates significantly to a fall in the employment share of routine manual task-intensive jobs in high-income economies, but not in emerging market and transition economies.

\section{About the Asian Development Bank}

ADB is committed to achieving a prosperous, inclusive, resilient, and sustainable Asia and the Pacific, while sustaining its efforts to eradicate extreme poverty. Established in 1966, it is owned by 68 members -49 from the region. Its main instruments for helping its developing member countries are policy dialogue, loans, equity investments, guarantees, grants, and technical assistance. 